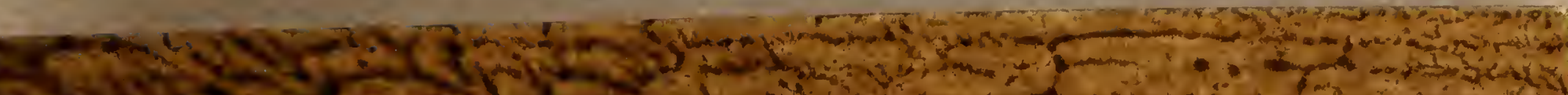

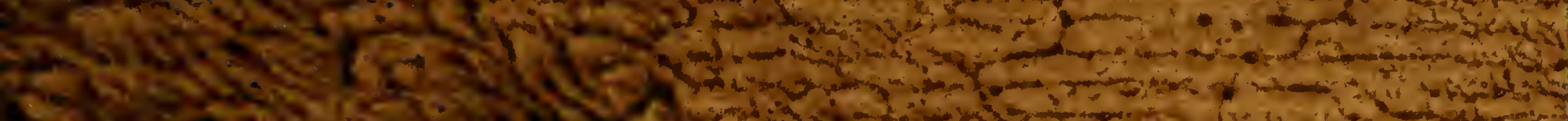

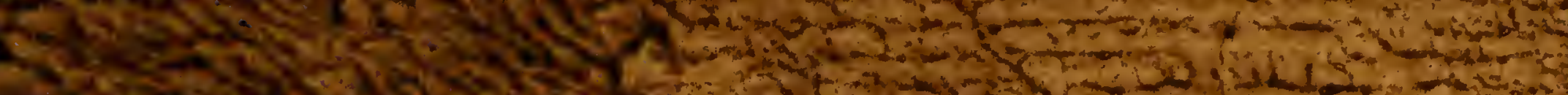

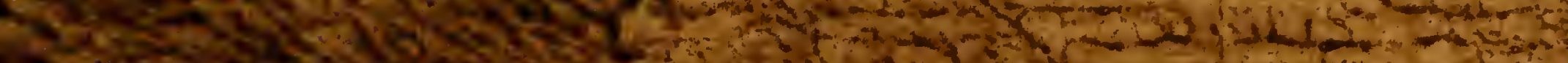

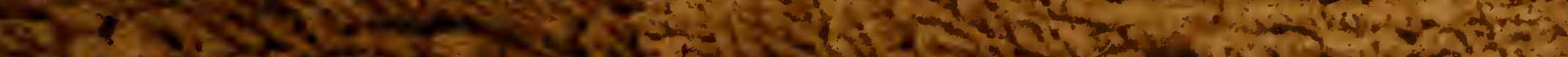

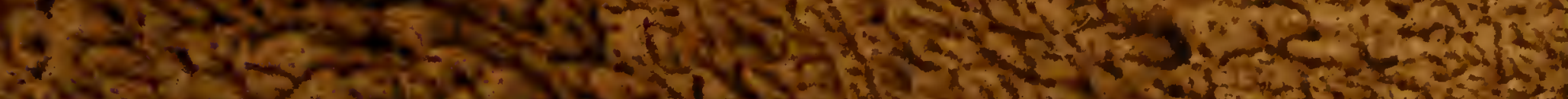

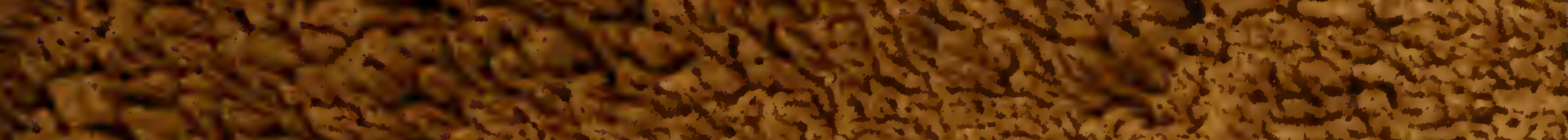
S.

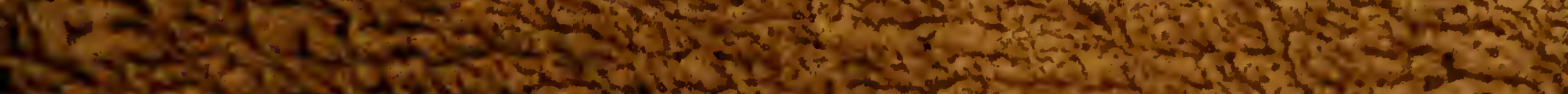

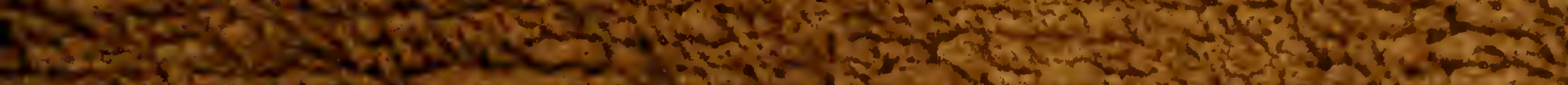

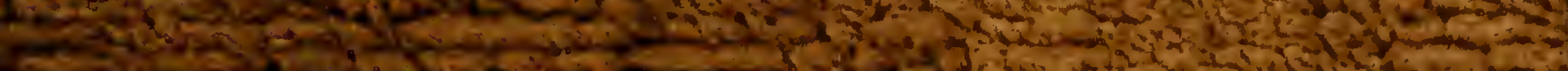

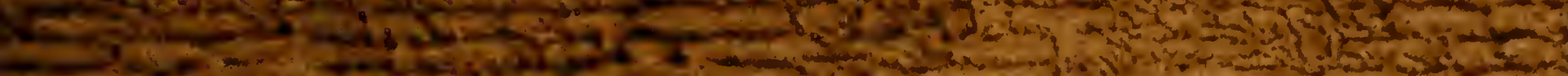

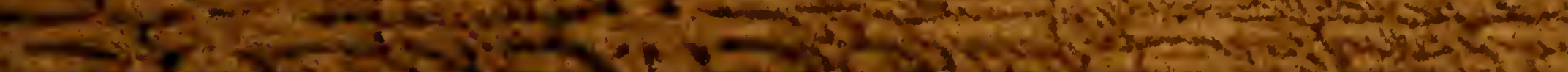

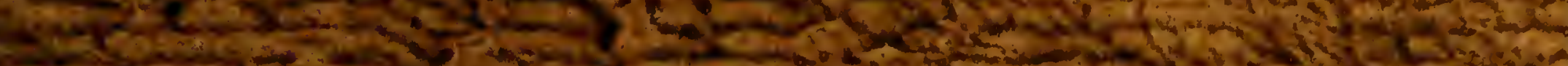

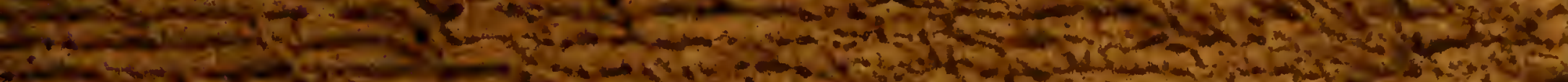
-

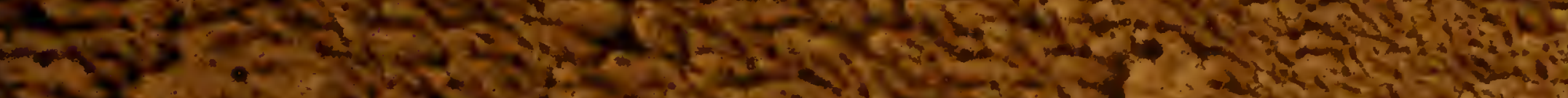

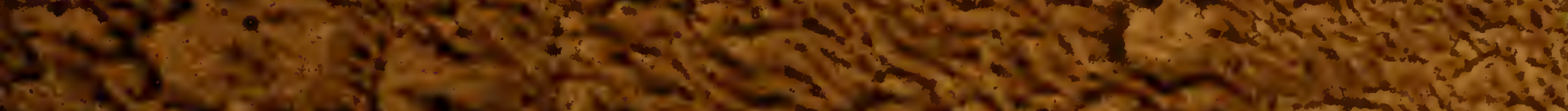
N.

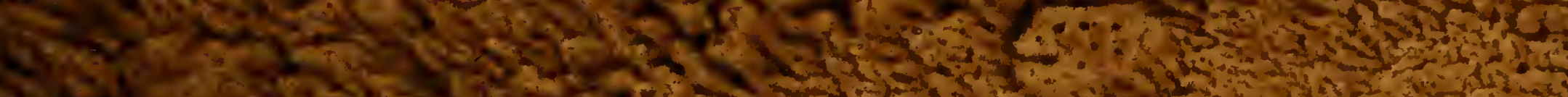

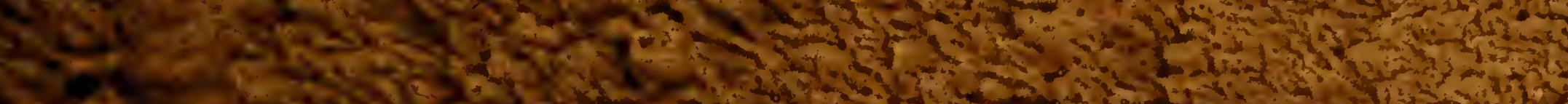

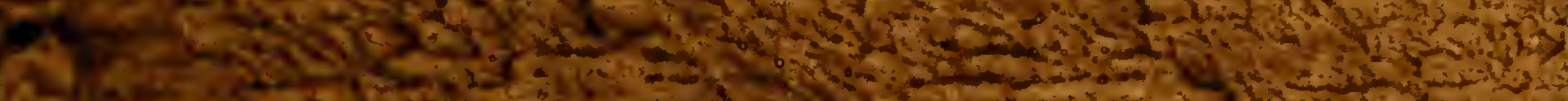
165

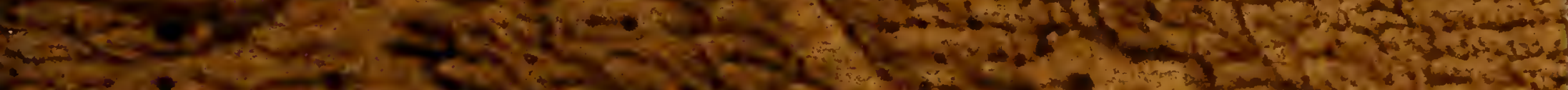
A.

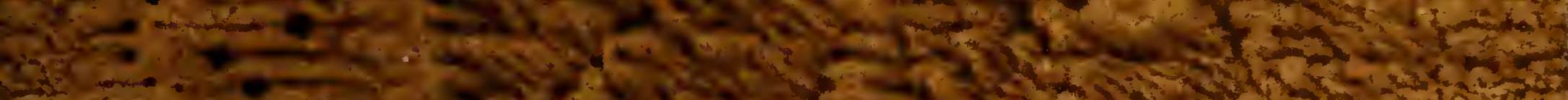

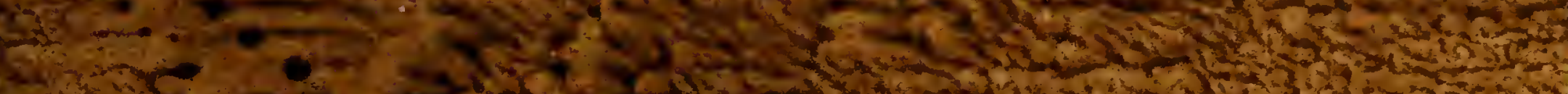

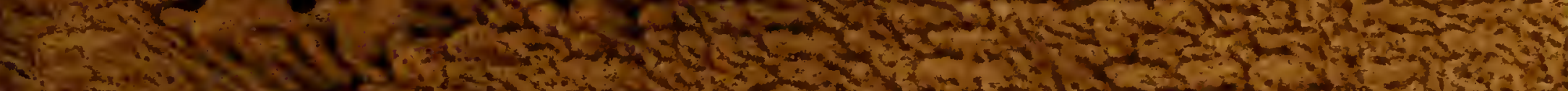

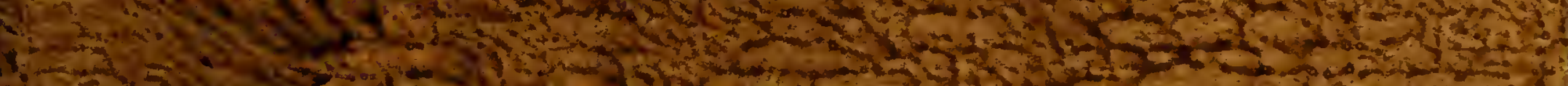

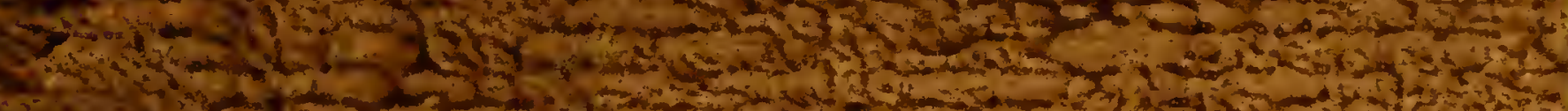

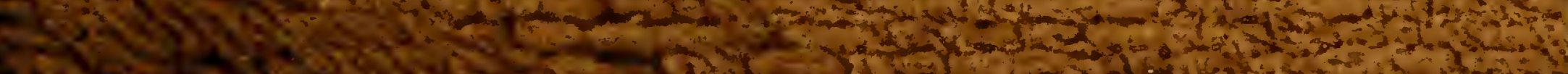

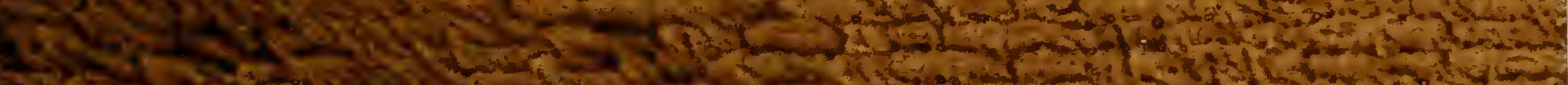

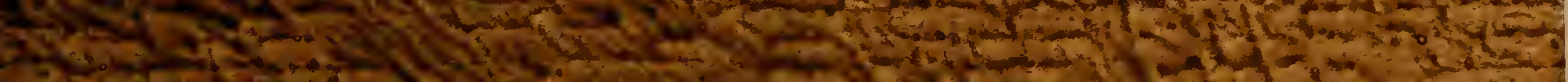

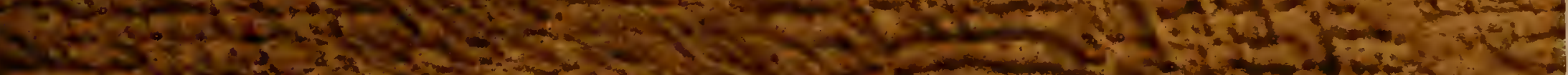
F.

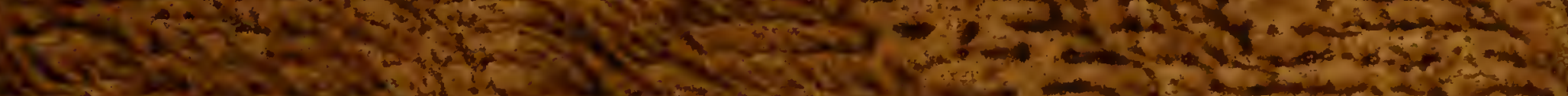

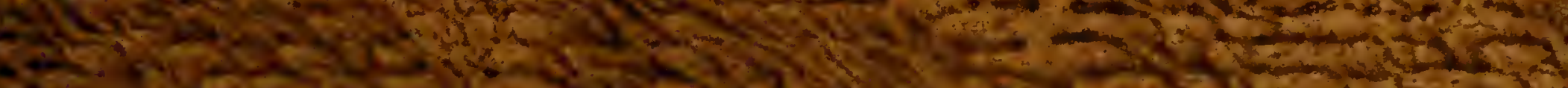
6-7.6.

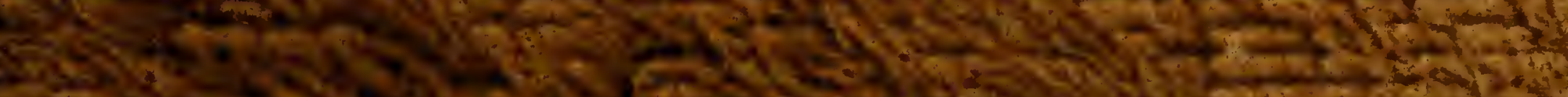

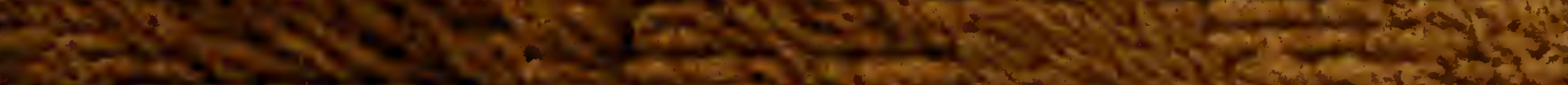

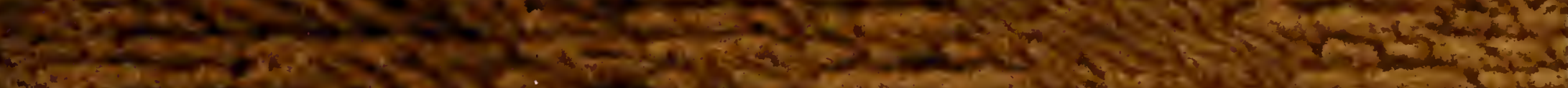

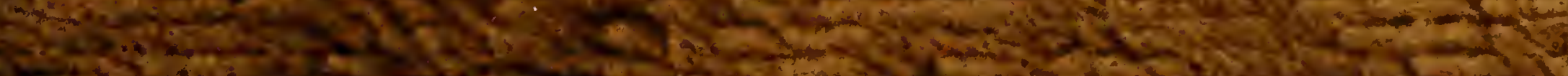

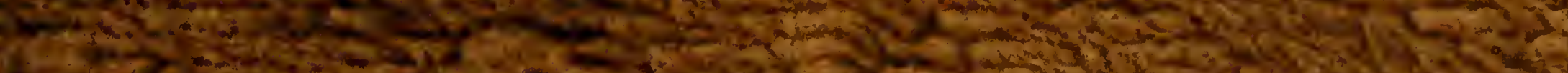

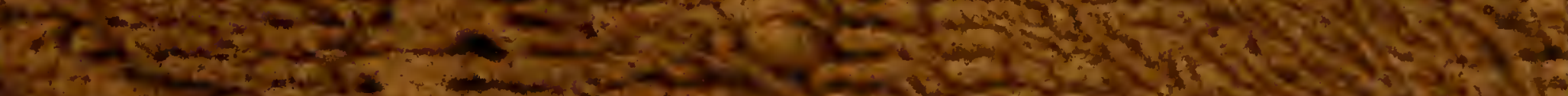

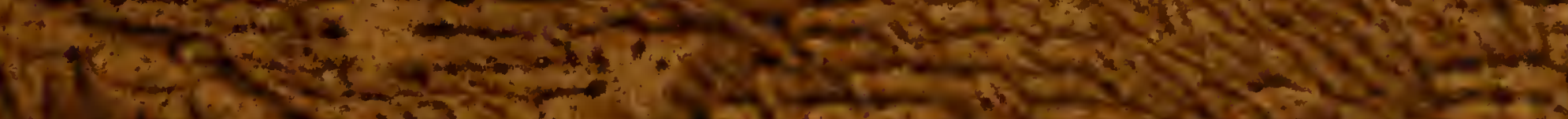

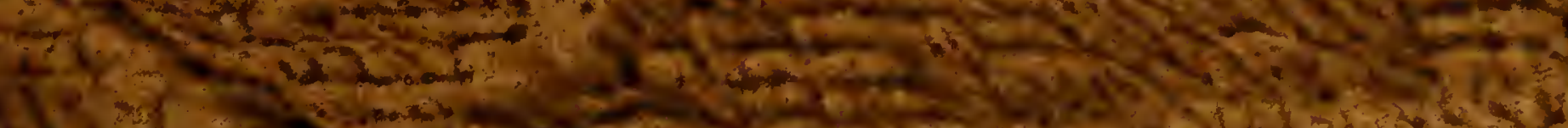

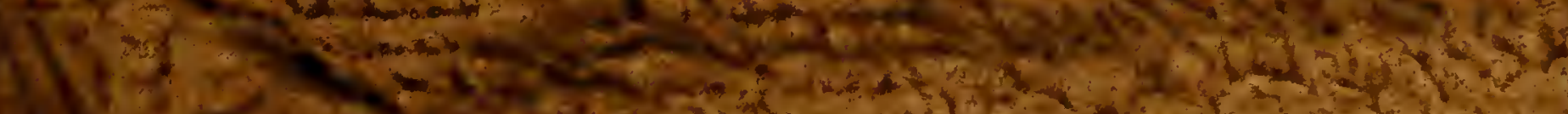

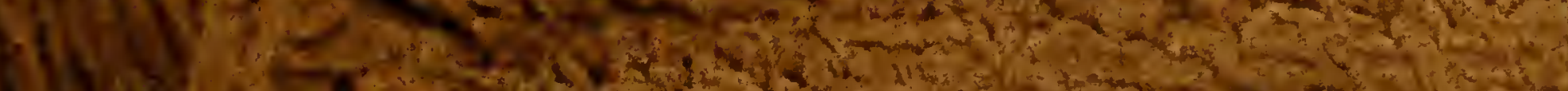

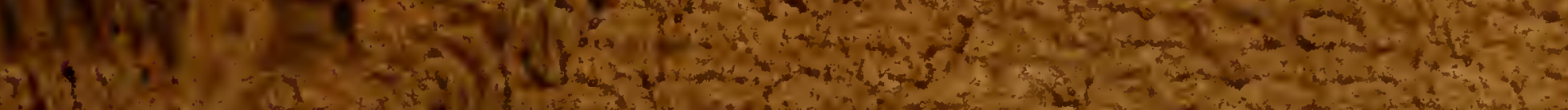

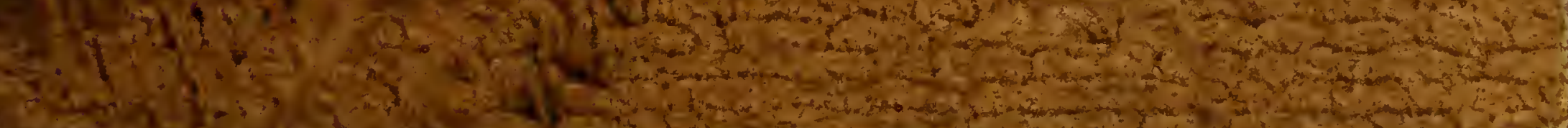




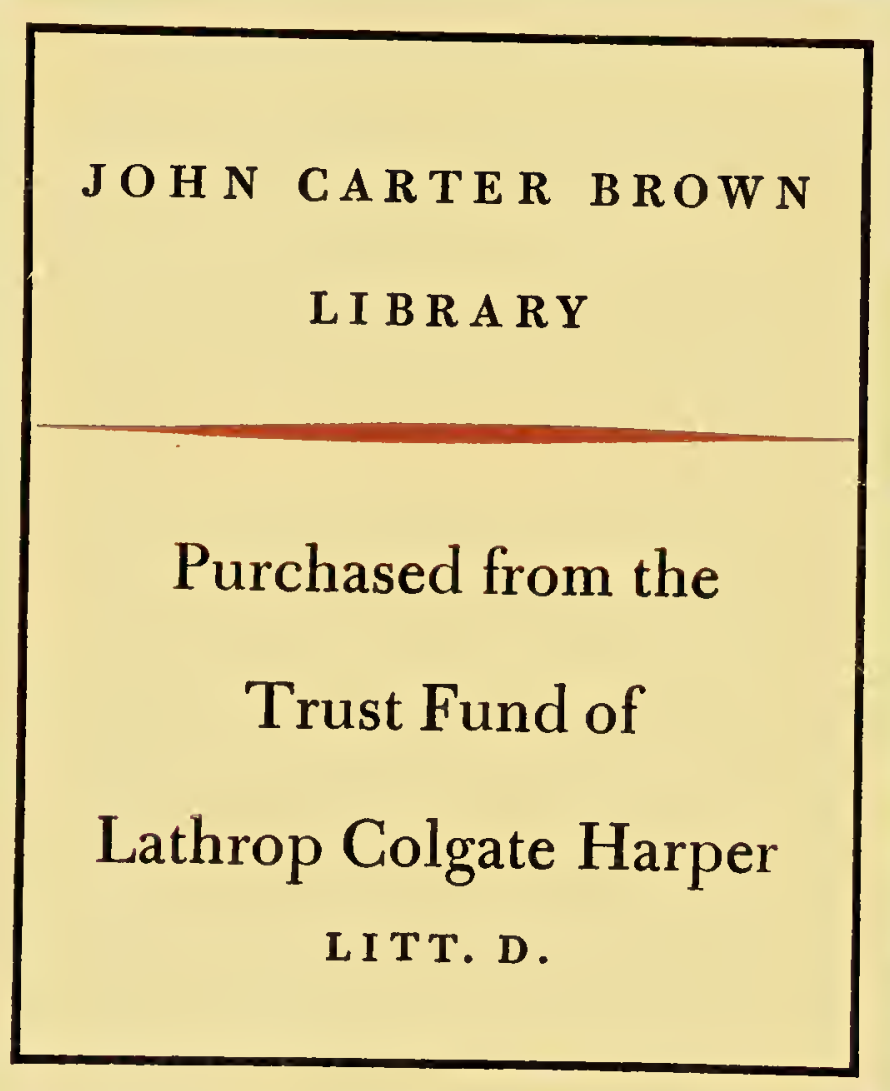





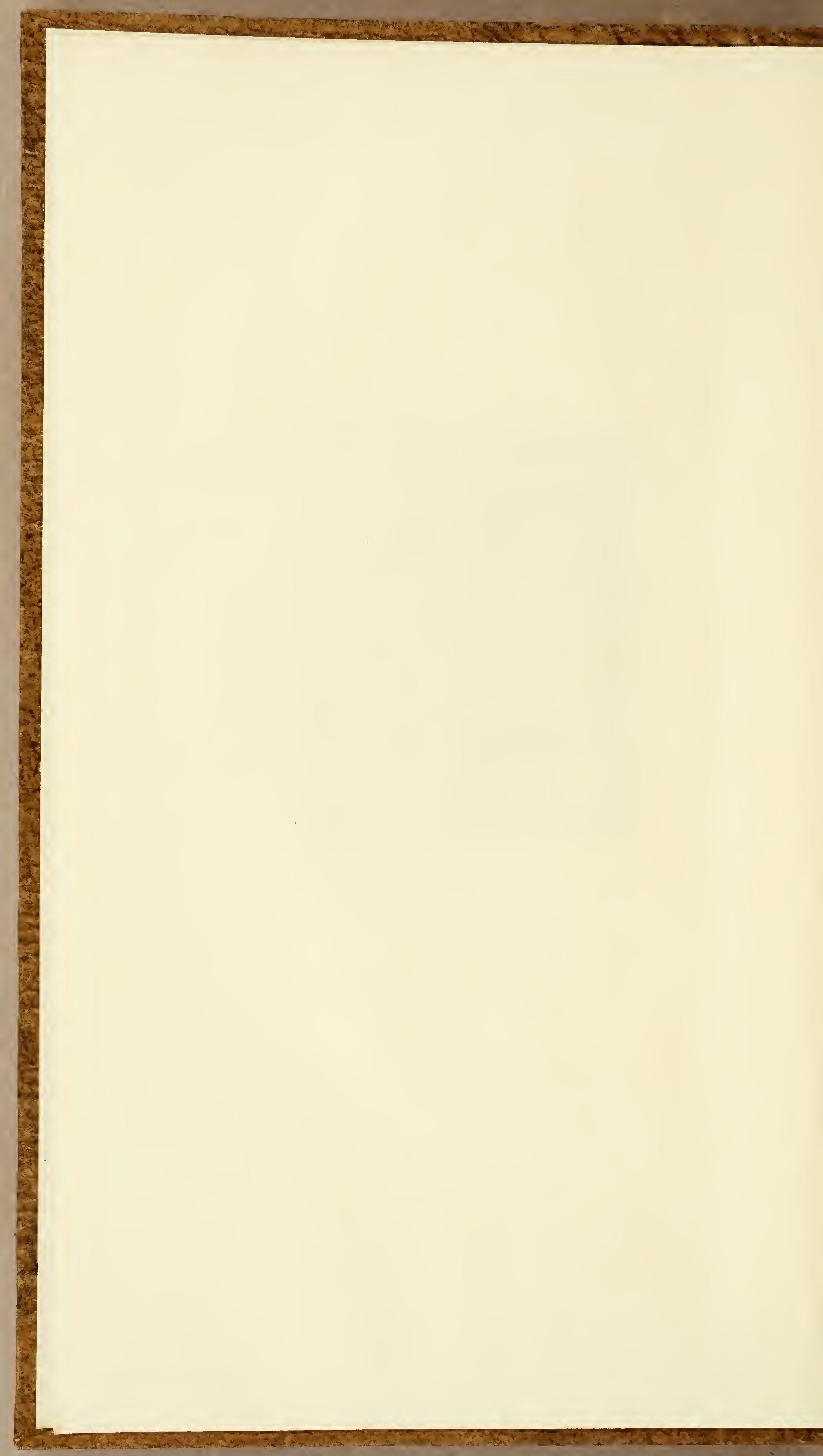




\title{
RESTAURATION
}

\section{DE L'A GRICULTURE}

\author{
EN F R A NCE; \\ E T
}

MOYENS DE PRËVENIR TOUTE DISETTE.

\section{Per me rutra vigent, iniè me amplaque regna fatif cunt. \\ PAR UN CULTIVATEUR, \\ Député à I’Affemblée Nationale,}

\section{A PAR S;}

Chez BAUDOUIN, Imprimeur de l'ASSEMBLée NAtionale, rue du Foin Saint-Jacques, $n^{0} \cdot 31$

$$
1790
$$




\section{TRADUCTION DE L'ÉPIGRAPHE:}

C'eft l'agriculture qui parle.

Je fais profpérer les campagnes; \& fans moì les plus vaftes Empires fe détruifent. 


\title{
A VERTISSEMENT
}

\author{
DEL'ÉDITEUR。
}

$\mathrm{O}_{\mathbb{N}}$ ne peut être heureux dans aut cun Empire sans la liberté, et sans l'abondance des denrées que la liberté favorise, encourage, et qui la soutient à son tour.

Quand les ennemis du bien public veulent détruire la liberté et affamer un Peuple, pour le mieux diviser, ils accaparent toutes les denrées de première nécessité, tels que les grains farineux d'hiver ; cela est très-bien vu dans leurs principes : mais ils ne. connoissent pas les ressources du sol, et l'industrie du Cultivateur prévoyant; elles sont infinies. Ils ne savent pas que les autres grains farineux que l'on sème au printemps, de même que toutes: les $\mathrm{A}_{2}$ 


\section{4}

racines propres à la nourriture des hommes et des animaux, nourriront tout le Proyamme, quand un hiver rigoureux, ou des vue et des opérations de ces gens mal-intentionnés amèneront une disette naturelle, ou, ce qui est encore plus affreux, une disette factice.

Une famille Belge a fait, à différentes époques, depuis plusieurs siècles, des opérations agraires si simples et si utiles, qu'elles ont beaucoup contribué à la richesse de la vaste Province qu'elle habite. C'est un des descendans de cette famille vraiment créatrice, qui expose, dans le Discours très-précis et très-sage que je publie, les moyens de ne jamais manquer de subsistances, d'obtenir et doubler en tout temps les plus précieuses productions, et celles qui peuvent remplacer notre nourriture ordinaire. Il reconnoit cepen- 


\section{5}

dant que cette grande ressource ne s'effectuera qu'autant que nous aurons brisé les chaînes de l'esclavage, et dissipé les ténèbres de l'ignorance. Il démontre que l'Amérique teinte encore aujourd'hui du sang des Negres, ne deviendra aussi étonnament fertile qu'elle en est susceptible, que quand elle sera cultivée par des hommes instruits el libres.

Pour que ces Pcuples réusissent, il faut que l'impốt soit simple et unique; il ne faut pas établir une dîme pour l'entretien du Culte, et un autre impôt territorial. Ce seroit deux dîmes pour une, ce seroit briser toutes les charrues, ruiner en peu de temps toutes les campagnes, et absorber toutes los avances du Colon riche.

Il est bien essentiel de ne mettre qu'une dîme en impôt; toutes les aul tres impositions pour subvenir à toutes

A 3 


\section{6}

les dépenses publiques, doivent être également directes pour ne pas retomber sur le Cultivateur; les impositions sur le luxe des édifices, portes-cochères, fénêtres, carosses, etc. sucre, café, liqueurs, provenant de l'Etranger, seroient les premières; les autres sur les vins, les eaux-de-vie de France, sur les comestibles \& productions du sol, qui diminuent d'autant le pécule dans la main du premier vendeur ou producteur, seroient les dernières. 


\title{
RESTAURATION
}

\section{DE L'A GRICULTURE}

\author{
E N F R A N C E.
}

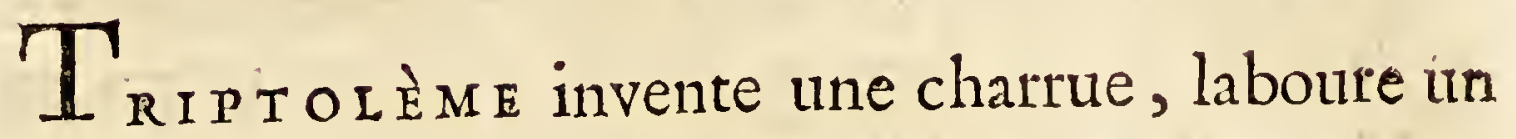
champ, qui produit de quoi nourrir ceux qui le regardent; les premiers parmi ceux-ci, qui fuiyent fes leçons \& fon exemple, fe trouvent plus à l'aife; bientôt les autres les imitent. Reconnoiffans de ce bienfait, les premiers Cultivateurs; tirés des hordes fauvages, qui peuvent célébrer. une fête, font de Triptolème un Dieú.

La première puiffance dans le monde connu; qui faifira ce point-de-vue, gui eft de rendre les hommes heireux, de les multiplier par l'exempte de la bonne a'griculture, \& l'augmentation des fubfitances, aura des autels qui ne finiront qu'avec les élémens.

On aura beau faire des loix pour affurer les fubfiltances \& le bonheur des hommes qui fouvent ne favent pas lire; la liberté, l'exemple, le 


\section{8}

feul exemple de la bonne culture, dans une habitation, dans un territoire, peut fubjuguer \& entraîner tous les efprits groflers \& récalcitrans, à toute exhortation écrite ou verbale, fans dire un feul mot, fans autres armes que la liberté \& l'exemple; il triomphe paifiblement des préjugés les plis anciens \& les plus enracinés.

Le mal-aife qu'éprouve le Colon indigent lui fait ouvirir les yeux fur fon voifin qui profpère; fi le labour de ce dernier réuffit quelque temps en cultivant la terre, l'autre effaiera de marcher fur fes traces, \& de faire comme lui (moyens, dé penfes, avances $\&$ accidens à part ), il parviendra à la fin aux mêmes réfultats; ils fe communiqueront de proche en proche, au point que tous les efprits du mệme village n'auront plus de préjugés, penferont \& agiront tous de même pour leur bienêtre réel, dependant feulement du ciel, du foleil, $\&$ de leur labeur.

Ce moyen fimple inftruit un village voifin; par la proximité \& l'enclavement du territoire, de voifin à voifin, linftruction fe répand fans aucune autre femonce que linfpection de la nonvelle culture de ce champ. Ces hommes fe croient libres, \& font heureux : maitres de leurs champs \& des productions qu'ils ont fait naitre, avec ha 
douce fatisfaction que tout vient de leur prévóyance \& de leur induftrie, fans avoir d'autre obligation à remplir que celle d'me recoinoiffance tacite $\&$ concentrée dans leur cœur, bien flatteufe pour celui qui en eft le premier mobile \& l'Auteur, qu'il ait befoin des bras \& des forces de tous ces hommes, ils voleront avec vivacité all-devant de rous fes defirs.

Voilà, mortels, quelque partie dı monde que vous habitiez, \& dans quelque climat que vous foyez, comme vous gouverneront ceux qui voudront vous rendre heureux, \& jouir eux-mènes de votre bonheur.

Un bon Agriculteur, à la follicitation du Souverain, peut fe placer dans un territoire négligé : fon exemple \& fes travaux vivifieront feuls un canton; cet homme peut former une pépinière de bons colons à tranfplaiter dans tout un Royaume, \& le faire profpérer.

Un Cultivateur riche en avances commencera à en faire l'effai fans fe rebuter; à la fin il fervira d'exemple \& d'inftuction à toute la communauté.

Mais le Souverain qui donne cette première impulfion, s'il n'encourage \& ne protège les premiers efforts, sil n'empêche point la rapacité avide 
\& la fombre envie de dévorer ces premières avances \& ces premiers fruits qui ont montré la vraie fource des richeffes, sil n'y met un frein, s'il n'affeoit un impôt territorial évalué en argent, fimple \& facile dans fa perception, tout fera bientôt tari \& détruit ; le champ défriché \& amélioré retournera bientôt à fon premier état de ftérilité.

O France! ô ma patrie! je gémis quand je yois tant de prés, de marais fous les eaux, tant de landes $\&$ de bruyères, tant de terres en friches quand je vois un tiers de tes terres en jachères; quel Royaume tu ferois fi tout étoit vivifié, cultivé, comme il peut E doit l'être!

Le travail que j'entréprends doir être étayé de plus grandes connoiffances, \& d'un ftyle que n'ont point les gens de mon état. Fils de Cultivateur, dont le père \& les ancêtres, en fuivant la marche de la nature \& de la probité, ont toujours affez réufli dans leurs travaux, je vais effayer de me rendre intelligible.

Il eft évident qu'on doit commencer par cultiver les bas-fonds. Les prés ordinairement avoifinent les rivières; on trouve plus aifément de quoi y nourrir \& y multiplier les beftiaux; ce qui donne l'aifance de cultiver enfuite les autres. D'ailleurs, une terre vierge, adamique, \& qui eft 


\section{I}

inculee offre les plins giands avantages au défrichement; tous les fucs, tous les fels y ftagnent, y font incorporés depuis long-temps : les bas-fonds contiennent bien plus ces principes que tous les autres terreins. La culture va les mettre en action \& produira les récoltes les plus merveilleufes; toute l'attention du Colon eft d'en comnoitre la nature.

Il eft également évident qu'un excellent pré qui produir du foin très-ficculent \& en abondance, fans aucun fecours, fains aucun frais, ne doit jamais être défriché; fi la mouffe l'étouiffe, on pent le mettre en culture pendant deux ou trois ans, particulièrement file fonds elt pure glaife ou argille froide.

La première année, avant ou après l'hiver, retournez-le à la bêche on à la charrue; enfuite au printemps, enfemencez-le encore en avoine; la feconde année, mettez-y une orge printannière; la troifième, enfemencez-le encore en avoine, dans laquelle on sème quinze ou vingt livies de treffle à l'arpent de cent perches, qu'on donne en verd alr gros bétail, tant qu'il dure; enfuite, il en broute le regain jufqu'à ce que la terre fe fourniffe d'herbes, \& redevienne encore in plus excellent pré qu'il ne l'étoit avant le défrichement. 


\section{2}

Si on veut le rendre plus profitable, on doit l'aider du parque des montons, de cendres de tourbes, de cendres-houilles, rouges \& noires, de fuie de cheminée, \&c.... Un an ou deux de cette cúlture fuffit pour rajeunir ce pré totalement.

Toute terre en friche, non labourée, sèch́e; fur le roc, fur le tuf, les rocailles, les cailloux arides, les fables fecs $\&$ infertiles, quand la charrue ne peut en retourner une certaine profondeur, doit être plantée en bois, ou refter comme elle eft, pour être broutée par les chèvres, les moutons, \& tout menu bétail, dans quelque expofition qu'elle foit.

Toutes autres terres en prés, marais ou en friche, limoneufes, argilleufes, glaifeufes, fortes ou légères, au midi cu au nord, crayonneufes, marneufes, pierreufes, peuvent \& doivent être défrichées pour le plus grand profit, à moins qu'elles ne foient fous les eaux; \& celles-là étant defféchées, deviendront les plus fructueufes \& les plus profitables. Dans tois les bas-fonds, il fe troave des tourbières qui ferviront, $x^{\circ}$. à chauffer le Peuple; $2^{\circ}$. aux manufactures, aux brafferies; $3^{\circ}$. cuire la tuille, la brique, la chanx; $4^{\circ}$. à fondre les métaux, excepté l'or \& l'argent, que la tourbe, chargée de bitume', de fouffe \& de vitriol, noircit? 
$5^{\circ}$. aux verreries, \&c. Les autres terres que les eaux découvriront, feront mifes en prairies ou en culture, ou plantées en bois, fur-tout le long de tous les canaux, folfés, rigoles ou étangs, néceffaires au defféchement, ou à l'écoulement des eaux, dont on fuivia la pente qu'on connoîtra par le cours des ruiffeaux ou rivières, ou en nivellant le terrein.

Il eft inconcevable que fi peu de Souverains aient encore pris ces bas-fonds en confidération; tous les ont regardés comme des terreins perdus \& de peu de valeur. Ce font cependant les plus précieux, \& ceux qui rajeuniroient tous les autres déja mis en culture de longue main; \& defquels on peut tirer plus de produit \& de profit, foit par les nouvelles prairies excellentes qu'on gagne, \& la multiplication des beftiaux de toute efpèce, le commerce de la cire \& du miel, foit par les terres graffes \& neuves qui produiront tous les grains huileux pendant un très-long terme, fans aucune interruption; point de fole réglée, point de jachères, foit par les cendres excellentes que fourniront les tourbières; enfin par l'augmentation des bois d'aulnes, peupliers, faules, ofiers, frènes, bois blancs, \& tous antres bois aquatiques.

Il n'eft pas néceffaire d'armer des vaiffeaux en 
guerre à grands frais pour-aller au loin difputer à quelques hordes fauvages, des terreins qui ne font peut-être pas auffi fructueux que ceux qui font répandus dans toutes nos Provinces, dont l'infalubrité eft occafionnée par ces cloaques infects, qu'on rendroit à la fin très-falubres \& remplis d'excellens poiffons; l'impôt territorial, évalué en argent, dédommageroir bientôt le Souverain de toutes fes avances foncières, fecourables \& protectrices.

La méthode que je vais propofer n'eft point la plus difpendieufe, ni la plus difficile; elle eft connue il y a long-temps, elle eft la plus fimple \& la plis aifée.

Mon refpectable père, qui a vécu près de quatre-vingt-dix ans, n’a jamais cultivé alitrement, quoiquil ait eu deux \& trois exploitations en trois ou quatre Paroiffes très-différentes par la nature de leur fol : fa pratique \& fon expérience, étoient étayées de colles de fon père \& de fon grand-père fur - tout, qui avoit vécu autant que lui (lequel la tenoit de fes ayeux); il eft le premier qui ait ofé femer le lin, colfa \& autres grains huileux dans un canton ce la Flandre. Ses defcendans ont tonjours cultivé de même \& ont soujours réufil, de forte qu'en datant de mon 
bifayeul, cette agriculture, toujours continuéc de père en fils, peut former l'expérience de plus de deux frècles; ce qui n'eft pás un court terme d'épreuves conftantes \& non fufpectes. Quoique je commence mon douzième luftre, je n'ai jamais vu que cette méthode ait manqué ni à moi, ni aux autres; c'eft parce que cette expérience de ma famille eft fure, que je n'héfite pas à la propofer à tous autres pour modèle, fauf à rectifier par l'intelligence ce que le pays \& le climat ne pourroit admettre.

\section{ARTICLE PREMIER,}

\section{Sain-foin.}

Dans les fonds cultivables les plus fecs \& les plus arides, tels que les marneux, crayonneux; fablonneux, pierreux, caillouteux \& légers, qu'on peut retourner à la charrue, l'herbe la plus profitable pour tout bétail, bêtes chevalines, à cornes $\&$ à laine, eft, fans contredit, le fain-foin verd ou fec: il eft une des premières verdures, c'eft le premier foin qu'on peut encore leur donner impunément auffitôt qu'il eft récolté; il les purge, les nourrit \& les engrailfe à merveille: in'y en a aucun dans toute l'économie rurale qui 
puiffe balancer fes avantages, pour augmenter les richeffes réelles du Cultivateur, qui font les betiaux maigres ou engraiffés, \& les élèves, fans jamais rifquer de les perdre par l'enfure, coup de fang, maladies de feu, \&c., accidens bien redoutables \& cependant bien fréquens par l'ufage de tout antre foin arcificiel, ou verdure broutée \& mangée par le bétail.

Il y en a de deux efpèces : le premier, plus commun, dont on ne tire qu'une première coupe ou fauchée, vers la Saint-Jean, quand il eft en pleine fleur, puis un petit regain qui eft encore très-précieux pour avoir de bon lair, du beurre délicieux l'hiver, \& pour engraiffer les moutons \& les bæuifs.

Le fecond, qu'on appelle en Flandre fain-foin de Barbarie ou de Hollande, dont la tige eft plus forte \& plus hante, qu'on fauche aufi quand il eft en pleine fleur, \& une feconde fois quand l'été n'eft point trop fec ni trop brûlant, qui donne enfuite un excellent regain à faire brouter au berail gros \& menu. Rien de fi nutritif que cette plante; rien d'aufi fain, verd ou fec; tous deux réuniffer tous les avantages que le Cultivateur peut defirer; rien ne peur les fuppléer pour leur excellence. 
Il faut avoir foin de prévoir un beau tèmps, par linfpection du baromètre, pour le faucher, \& le mettre enfuite en javelle avec le rateau. On a la précaution de ne pas le retoumer dans la plus grande chaleur du jour, de peur de perdre les petites fetilles adhérentes à la tige, qui rendent le foin très-nourriffant; on le met en tas ou en monts, faits en pointe, de la groffeur de deux ou rois groffes futailles à l'eaut-de-vie de fix à fept pieds de liauteur, qui infenfiblement s'affaiffent. On évite auffi bien la rofée que la trop grande chaleur pour cette opération, dans la crainte qu'il ne devienne poudreux. Quand les monts font bien affermis, on choifit un beau temps pour l'engranger \& l'entaffer, en le faifant bien piétiner par des hommes forts \& robuftes. Cette befogne eft peu différente de la récolte des foins ordinaires, fi ce n'eft qu'elle eft plus fimple \& plis expéditive.

Toute terre donc, femblable à cet article premier, en plaine unie ou en pente, au nord ou au midi, doit être défrichée \&r retournée au printemps, à la bêche ou à la charrue, de préférence cependant avant l'hiver : il faut la femer au printemps en avoine à la herfe, l'année d'enfuite en farrafin ou bled noir; quand le gafon eft bien Reftauration, \&c. 
pourri, la terre bien nette, on met huit ou dix woitures de fumier bien pourri, par arpent, qu'on enfouit à la charrue; on enfemence de nouveau cette terre en avoine, \& en même temps on $y$ joint une livre de graine de fain-foin par perche de vingt pieds, ce qui fait au moins cent livres par arpent de cent perches; femez ce fainfoin immédiatement après l'avoine, au mois de Mars ou d'Avril, par un beau temps, on herfe légèrement un tour ou deux, puis on paffe le rouleau fur le terrein.

Si la terre eft trop sèche \& trop aride, on sème feule la graine de fain-foin au mois d'Octobre; fi, au demi-printemps, elle n'étoit pas levée affez drue, on resème alors la moitié de la graine que l'on a mis au mois d'Octobre.

Tant que les mauvaifes herbes n'étouffent pas le fain-foin, on en fait fon profit. Cette plante peut durer, ainfi que la luzerne, 4,6, IO, Is ou 20 ans, felon le pays \& le fol. Quand les mauvaifes herbes fe gafonnent autour \& l'étouffent, il eft temps de retourner alors ce champ à la charrue avant l'hiver. On doit au printemps fuivant l'enfemencer de nouveau en avoine, l'année fuivante en feigle, \& enfin en farrafin; après les trois 
19

annees, on remer encore cette rerre en fain-fors ou en luzerne.

Les meilleurs engrais pour le fain-foin forr les cendres de rourbes, de bois, de houille noire \& rouge, de fuie de cheminée qu'on voicure pendant l'hiver. Au printemps on laiffe mûrircette plante, il ne faut pas attendre fa trop grande maturité pour la faucher, car elle s'égraine facilement; on la met par javelle à la rolée, puis on la bat firr-le-champ.

La graine eft bonne à donner aux chevaux au lieu d'avoine; il faut pour cela qu'elle foit fort abondante $\&$ à bas prix : la tige battue eft bonne pour le bérail, les feuilles \& les poumières ne font pas même à négliger; on les fert pour l'hiver, les vaches \& les moutons en tirent encore une bonne nourriture.

\section{$A$ R T. I I.}

\section{Luzerne.}

La luzerne réuffir dans les fonds marneux; pierreux, crayonneux, glaifeux, mêlés de marne, dans les terres argilleufes, limoneufes, \& mieux généralement dans les fonds fubftanciels \& roides, que dans ceux plus légers. Dans les fonds gras \& 
féconds, les mauvaifes herbes l'étouffent bien vîte, elle ne dure pas fi long-temps; il faut prendre garde qu'elles n'y pullulent, autrement au bout d'un an ou deux elle périt. On sème au printems quinze ou vingt livres de feize onces de Luzerne à l'arpent de cent perches, la perche de vingt pieds dans une terre bien nette, bien meuble \& fort adoticie à la herfe \& au rouleau : on la sème, dis-je, dans l'avoine, quand celle-ci en haute de trois pouces, ou dans le lin, ou même feule. On 'empêche la première année les moutons d'y paitre, \&c on aura une bonne récolte le printems fuivant, fi on a foin de l'engraiffer pendant l'hiver avec des cendres de tourbes de Hollande ou du Pays, avec des cendres d'houille rouge ou noire, avec de la fuie de cheminée, du crotin de pigeon; au printems, avec de l'urine de bettianx, des vuidanges graffes, des mares de foffés \& de latrines, \& avec du roufi de fumier délayé avec des tourteaux ou gâteaux de marc de colzat, de chénevis ou de linette. Quand on n'eft point à portée d'en'avoir, un feul ou deux de ces engrais fufffent chaque année; fans grands frais on peut fe bomer à des cendres de tourbes qu'on répand tous les hivers \& tous les printemps.

C'eft la première de toutes les prairies arti- 
ficielles à donner aux vaches; it eft vrai qu'clles ne donneront pas d'auffi bon lait $2 x$ d'aufi bon bearre quavec le fain-foin \& le trètle verd; mais comme cette plante paroît la première, elle donne le moyen d'attendre les autres verdures. C'eft un excellent foin pour les chevaux, il leur donne beaucoup d'embonpoint $z x$ de vigueur; il faut cependant lui laiffer jetter fon feu dans le tás ou dans la meule pendant un mois ou deux, avant de la leur faire manger; il pourroit occafionner différens maux.

L'avantage fingulier de la lizernc bien fumée eft d'être fauchée trois oul quatre fois; un atpent pent produire en foin ou en verdure autant que trois bons arpens de toute antre prairie naturelle : voili pourquoi il eft toujours bon d'en avoir poir. la multiplication des boftiaux ; elle fupplée an fain.. foin \& an trèfle, qui quelquefois manquent on ne réuffiffent point ; il faut remarquer qu'elle eft très-dangereufe à faire bronter en verd par les vaches \& moutons : elle les gonfle comme un ballon, \& les fait créver en très - peu de temps par la fermentation excefive qu'elle excite dans leurs eftomacs. Les conducteurs de ces animanx doivent être fort pridens, circonfipeds \& arten-. $\mathrm{t}^{\mathrm{i}} \mathrm{s}$ pour les y faire manger; car une henre funt 
pour perdre tout un trouipeau de bêtes à laines ou a cornes. On doit attendre les gelées, \& on évite de leur mettre le nez au vent, fur-tout quand il eft au nord; on les chaffe de temps en en temps fur les chaumes, ou fur les jachère: voifines.

Au refte, on doit avoir la même précaution pour faire paitre des trèfles; une Luzernière peut durer, ainfi que le fain-foin, cing, dix, quinze ou vingt ans, quand therbe ou la dent du mouton ne la font point périr; on la fait faner aufi comme ce dernier. On la lie quelquefois en bottes pour la metrie en meule ou en grange, elle s'entafre alors mieux. C'eft un trèsbon foin pour les chevaux, lhiver \& le printemps; il échauffe, anime, nourrị \& engrailfe; fur-tout quand il n'a pas eu de pluie, \& qu'il n'eft ni poudreux, ni moifi; il eft bon aufi pour les moutons.

Quand la luzerne ne produit plus abondam ment, \& qu'elle eft trop enherbée, on la retourne à la charrue; cette terre alors rapporcera de bonnes avoines \& de hons colzats, enfuite des feigles, des vefces mêlées de feigle, \& enfin du froment, fla nature du terrein le permet. Si cctie terre eft bien nette \& aidée de 
bons engrais, elle produira autant que d'autres bonnes terres en culture, fur - tout fi le colzat fufdit eft cultivé à la manière flamande, comme elle eft enfeignée dans le journal d'agriculture; par M. l'Abbé Roubaut, mois de Février $177^{8}$, page 65, \&c. C'eft la meilleure méthode \& la plus profitable pour rajeunir le fol ; on ne faurois affez la faire connoître.

\section{$A \&$ T. I I I.}

\section{Trefle.}

Le trètle demande une bonne terre $\&$ de bons fonds, fur-tout d'argille un peu roide, rouge $\&$ en bon état de culture \& d'engrais; il ne convient pas du tout dans un fonds marneux, crayonneux, pierreux, \& généralement dans toutes les terres forr légères \& sèches, c'eft-à-dire qu'il n'y réuffit jamais auffi bien; cette plante eft bien plus friande que la luzerne \& le fain-foin: ce dernier fur-tout qui vient parfaitement bien dans toutes les terres prefque infertiles, les rend même fufceptibles, quand on les défriche, de porter avec profit d'autres grains, tels qu'avoine, farrazin, feigle mêlé de lentilles \& vefces.

Le trètle cependant eft, après le fain foin , b 4 
la meilleure nourriture à donner en verd dans l'étable aux vaches \& aux chevaux; il fournit de trèsfon beurre \& dans la pius grande abondance; on le coupe quand il eft en pleine fleur, jufqu'à deux \& même trois fois, fur-tout quand on l'aide, comme la lnzerne, de cendres \& des mêmes engrais avant \& après l'hiver ; il eft plus difficile à récolter fec que le fain-foin; avec du beau temps on en vient cependant à bout, quand il a effuyé beaucoup de pluie; il eft poudreux, mauvais \& dangereux, principalement pour les chevaux, ainf gue le foin de luzerne: il faut auffi le laiffer fuer an tas, un mois ou deux. Sil eft poudreux, on le donne I'hiver aux varhes \& aux moutons; après l'avoir fecoué avec attention; fa fenaifon \& fa récolre font les mêmes que celles du fain-foin $\&$ de la luzerne, fi ce n'ert qu'il faut le remuer \& le retoumer tant qu'il foit aufi fec que le foin de Pré, pour le mettre en monts ou petits tas. Dans le champ même le dernier regain qu'on ne fanche pas, eft une bonne nourriture pour les vaches \& poü les moutons; il faut les mêmes précautions pour le faire brouter, que pour la luzene afin de ne pas les perdre par l'enfure.

On seme quinze ou vingt livres de trètle à larpent de crence, au printemps, à la veille d'une 
pluie, dans les avoines levées, dans les bleds \& dans les feigles verds : on paffe légèrement un trainoir fur le femis: quand on veut en tirer de la graine, on ne fauche pas ordinairement la feconde coupe, on la laiffe mûrir à fond; on bat la graine l'hiver par. une gelée sèche, on sème la paille courte, on la goufle au mois de Février dans les Prés ou dans les bleds verds, \& fouvent il réuffit mieux que de femer la graine pure. Après la moiffon, on a quelquefois un bon regain à faire paitre, puis l'année d'après il eft dans toute fa force; l'année fuivante, on le fait manger par les agneaux ou autre bétail jufqu'à la Saint-Jean; on le retourne avant l'hiver pour en tirer une très-bonnẹ avoine ou un bon lin non ramé.

$$
\begin{aligned}
& \text { A R T. I V. } \\
& \text { Ray-Graffe. }
\end{aligned}
$$

Le ray-graffe ou faux bled, dont la graine coit être tirée d'Angleterre, réufit dans tous les fols, \& donne un excellent fonmage pour les beftinux; fa culture, fa récolte eft la même que celle du fain-foin ; on doit avoir la précaution de le faucher quand lá tige commence à contenir l'épi formé: 
on peut le faire paître en verd au commencement du printemps; verd ou fec il fortifie, entretient en bon état \& engraiffe. Cette plante réfifte quelquefois, quand les trois autres périffent par un hiver rigoureux; elle eft encore de la plus grande reffource pour le laboureur, mais bien des perfonnes s'en paffent.

Au refte, dans toute exploitation il faut réunir Ia culture de ces efpèces, principalement des trois premières, pour la nourriture \& la multiplication des beftiaux, parce que l'un fupplée toujours au défaut de l'autre; tous ne réuffiffent pas toujours également chaque année. L'Agriculteur qui multipliera fes beftiaux élevés chez lui, par ces nourritures \& les autres que je vais citer, fera tout profpérer dans fes terres enfemencées, foit de bled, de feigle, d'avoine, de colfat \& de lin', \&c. Par l'abondance des fumiers \& des engrais de toute efpèce, il engraiffera des beftiaux à volonté; il choifira, par curiofité, pour élèves, les plus beaux dans chaque efpèce, fans jamais être dérouté fans jamais être pris au dépourvu. Ses voifins émerveillés, en feront autant, \& bientôt toute une Province pourra l'imiter \&-s'enrichir à fon exemple. Qui empêche qu'une Province voifine fuive la même méthode, $2 x$ très-facilement, par le com- 


\section{1}

merce \& les relations qu'un voifin a effentiellement avec fon voifin, \& enfin tout un Royaume.

Tout ce que j'ai propofé jufqu'ici n'a rien de commun avec les terres ordinaires en droite fole ou en jachère; ce que je vais dire dans les cinq arricles fuivans, n'y aura pas plus de rapport; c'eft-à-dira que les terres en bled ou en avoine; condamnées au repos (par l'ignorance, la pauvreté, ou l'impôt mal affis \& arbitrairement perçu), feront toujours cultivées à l'ordinaire : je n'y dérange rien, ou bien peu de chofe; cependant par gradation \& avec le bénéfice des engrais \& la multiplication des beftiaux, infenfiblement toutes les jachères diminueront, jufqu'au point de les fupprimer entiérement; le tout au profit du commerce. Les denrées capables de vivifier les manufactures, telles que tous les grains huilleux, comme chanvre, lin, colfat, camomille, eillettes, \&c. La régénération \& l'amélioration des troupeaux, \& la fineffe des laines que le fol de la France peut produire avec autant \& plus d'avantage que l'Efpagne \& l'Angleterre, feront une nouvelle fource de profpérité que je veux trouver dans la troifième partie du fol, qui forme les jachères ou l'année de repos : on trouve encore plus aifément ces richeffes, qui vont animer l'inertie des jachères, dans 
le défrichement de touls les marais noyés fous les eaux, formés en pré naturel, ou prairies artificielles, ou en culture ordinaire; ils domeront des nourritures nouvelles pour multiplier le bétail, les fumiers, \& les fubfiftances des hommes; toutes celles propres à être mifes en bonne \& floriffante culture, fans ces apprêts, n'y dérangeront rien; tout aul contraire, en agriculture, une parcie défrichée, anime, vivifie l'autre qui eft en culture; rien d'inutile, point de coup perdu.

Je m’arrête. Rien de tout ceci n'arrivera, fi le Souverain ne tient point le timon de l'Etat, sil ne protège \& n'encourage le laborieux Cultivateur. Hélas ! il peut le faire de la manière la plus aifée \& la plus fimple : c'eft de lui permettre de vendre librement fes denrées, c'eft de l'empêcher d'être vexé, ruiné \& avili par les fuppôts de la chicane qui, s'impatronifant dans une honinête famille, comme font les chenilles dans un jardin rempli dé légumes, d'excellens arbres fruitiers, commencent par en ronger les fetilles, puis les fruits, \& en peu de temps defisèchent $\&$ dévorent le tronc \& les racines.

C'eft ici qu'un Monarque éclairé doit prendre la coignée du Sauvage de l'Amérique, dont Montefquieu fait une application fi jufte; c'eft 
ici, dis-je, qu'il doit frapper avec des bras d'Hercule, \& délivrer l'univers de cette hydre mattdite, de ces exécrables harpies, oifeaux plus fombres \&x plus funèbres que ceux du lac de Stymphale, portant la trifteffe, la défolation \& la mort par-tout où ils fe montrent.

Heureufes les Nations où un Héros pacifique, un Roi fage faura prendre la réfolution ferme de couper toutes les têtes de ces monftres odieux, \& de détruire à jamais dans fes Etats tous les germes de cette horrible engeance. Supérieur à Cadmus, qui n'avoit d'autre talent que de faire naitre des hommes, il aura celui de les multiplier, de pourvoir à leur fubfiftance, de les empêcher d'être dévorés par les plus infâmes dragons. L'apothéofe qui couronna les travaux d'Hercule, n'eft qu'un foible hommage au prix de celle qui fera due par les mortels à ce Héros bienfaifant.

O fages defcendans de Guillaume Penn! ne vous laffez point de verfer votre fang pour conquérir la liberté que l'Auteur de la nature a donnée à tous les êtres. Si l'Europe tarde trop à feconer le joug des préjugés \& des preftiges qui rendent les hommes foibles \& pufillanimes, vous aurez la gloire de lini en donner l'exemple dans un vafte hémifphère. 
Après avoir annobli votre race par de fi pénibles efforts, après avoir établi un impôt unique \& fimple fur le revenu des fonds territoriaux, il vous reftera bien peu de chofe à faire pour le bonheur de vos defcendans; prenez les moyens fages d'empêcher à jamais que la rapacité des fuppôts de la finance \& de la chicane ne s'empare de vos foyers \& ne s'y établiffe, pour vous fubjuguer \& vous replonger dans les ténèbres dont nos régions font couvertes, que votre courage diffipe, \& dont je voudrois voir notre continent délivré. Empêchez par des Loix immuables que les Seigneurs féodaux n'arrêtent \& n'anéantiffent les premiers efforts du talent \& de la conftance par des vexations \& des tyrannies qui feroient tarir la fource de tous les biens; ne fouffrez pas que certains célibataires comblés des bienfaits du Gouvernement, aillent abforber les richeffes \& les avances de vos Cultivateurs, \& faffent fuir les riches Colons de vos campagnes; en affichant un luxe révoltant \& fandaleux dans des Provinces affermies au prix de votre fang; empêchez que leurs agens \& leurs efclaves ne dévorent les travaux \& les mifes de l'Agriculteur laborieux par l'inftabilité des baux, par des redevances \& des fermages exceffivement hauffés, \& 


\section{$3 x$}

fi exhorbitans, qu'un bon père de famille \& un prudent Adminiftrateur n'oferoient jamais les exiger. Ne fouffrez jamais que l'égoifme affreus qui dit, après nous le déluge, s'établiffe chez vous; il y produiroit plus de maux, il y feroit plus de ravage que n'a fait jufques aujourd'hui l'Anglois \& le fcapel du fauvage.

Il faur que chaque Colon foit maître de fon champ, comme il a le droit d'y extirper les mauvaifes herbes, d'y détruire les infectes, vermeaux, mufaraignes, \& tout ce qui peut nuire à fes efpérances \& fes récoltes, il doit avoir de même le droit d'écarter \& de tuer le lièvre, le lapin, la perdrix \& le faifan qui ravagent fes vignes, fes grains, à plus forte raifon, la biche, le cerf, le fanglier, le loup qui dévore fes brebis, \& enfin tout le gibier qui peut ravager fes moifons. C'eff ici que la fermeté du Gouvernement doit fe montrer invariable \& protéger avec vigueur le foible opprimé par le puiffant dépourvu de raifon $\&$ d'humanité : autrement les loix les plus fages font bientôt renverfées; un Seigneur féodal, jaloux de la chaffe, rracaffera, vexera \& ruinera, en peis de remps, le pauvre \& le riche Cultivateur.

Les gens de Loi, Greffiers, Baillis, Procureurs; 
Gardes, Sergens, tout le cortège de la chicane, qu'il a à fes ordres, vont bientôt afléger l'innocent Agriculteur d'un déluge d'écriture les plus uniformes qu'il n'entend ni ne peut lire; il aban. donne aufitôt en gémiffant les plus juftes prếtentions quie doivent mériter fes vigouretix tràvaux; il finit fouvent par être honni, \& par mourir dans la plus affreure misère, pour avoir défendu trop librement ce que fes bras, fes enfans, Dieu \& la nature avoient fait naître. Barbarie qui glace d'effroi tous fes femblables; injuftice, qui n'eft que trop commune dans plus d'un pays.

O Penfylvaniens, ennemis de l'oppreffion \& protecteurs des propriétés! vous peuplerez \& enrichirez, en peu de temps, vos régions de la claffe la plus laborieufe \& la plus intelligente des Européens qui ont de l'ame \& du courage, à moins que des Loix plus fages de réformes, de protection \& d'encouragement n'oppofent une forte batrière à leurs émigrations (I).

(I) Note del'Editeur. L'Auteur écrivoit ceci en 1783 , ce qu'il difoit alors aux Américains peut très-bien s'appliquer aux circonftances actuelles de Ia révolution: 
A R T. V:

Pomme de terre.

Les terres limoneufes, fablonneufes, argilleufes; bien cultivées, bien netres \& ameublies, plus légères que roides, conviennent à la pomme de terre \& au topinambour. Ce fruit réunit tous les avantiges poffibles pour les hommes, les beftiaux $\&$ les volailles de toute efpèce; étant cuite \& broyée on en fait de très-bon potage pour les gens de travail avec légumes, comme cholix, navets, carottes \& ris en temps de difette ou de cherté de grain, elle y fupplée avec un grand avantage : toutes les moiffons feroient détruites par l'orage \& la foudre, par les tempêtes \& les grêles les plus défolantes, le Cultivateur trouveroit encore les pommes de terres, les carottes, les panais, les betteraves, les navets, quil'empêcheroient de mourir de faim, lui \& fon bétail; c'ent pourquoi on ne doit jamais négliger de cultiver ces racines, qui, hors de ces années de calamité \&: de défaftres, procurent tous les moyens faciles de s'enrichir par l'engrais des beftiaux, \&cc. 'La tige, au commencement d'Octobre, nourrit les vaches; le fruit cuit dans l'eau $\&$ broyé avec du fon, nourrị Reftaurat. de l'agriculture. Ec, C 
dindon, oie, chapon, canard \& toute forte de volailles. La pomme de terre engraiffe les porcs étant mêlée de mouture de feigle, d'orge \& \& farrafin. Si on en fait bouillir avec des tourteaux ou gâteaux de colf $\&$ \& de chenevi ou avec des criblures de linettes ou de la mouture de feigle ou de farrafin, elle engraiffe les vaches \& les bœufs; outre cela, on en fait d'excellent pain, d'excellentes pâtifferies, \& de très-bons mets, fort légers.

M. Parmentier de Paris a donné un très-bon traité fur cette fabrication qui ne laiffe rien à defirer; la pomme de terre donne encore d'excellent amidon à faire de la poudre pour les cheveux, ce qui eft encore un objet de très-grande économie. Je ne vois rien dans la nature qui puiffe dommer des bénéfices fi réels, \& en aufli grand nombre; un arpent de terre bien arrangé fournit plus de profit au Cultivateur, que toute autre production, excepté le lin rame', quand il réuffit. Sa culture eft la plus aifée, comme elle eft la plus fructueure. Les fonds fablonneux \& gras ou engraiflés, les fonds limoneux, \&x. font excellens pour cette plante.

Au mois de Février ou de Mars, par un temps fec, il faut labourer la terre qu'on aura bien fumée avant l'hiver, la rendre meuble $\&$ douce, la bien. 
herfer \& la bien nettoyer des mauvaires herbes: à la fin de Mars ou au commencement d'Avril, on doit, par un beau temps, sil eft poffible, enfouir à la bêche ou à la charrue les pommes de terres moyennes, ou les groffes coupées en deux ou en trois felon leur groffeur, \& les placer à trois pieds de diftance.

Quand la pomme de terre eft levée \& qu’elle pouffe en verdure, on prend une bêche on plutêt une houe, on extirpe tontes les mauvaifes herbes en ratiffant au tour de la plante fans l'étouffer; quand la tige eft élevée \& haute d'un demi-pied, on recommence cette opération, l'on ratiffe toiijours auprès de la tige pour y former une motte, où les pummes de terre fe plaifent à pulluler.

On redonne encore une troifième \& mêtme façon à la fin de Juin ou au commencement de Juiller, felon que la faifon s'avance plus on moins, emipêchant toujours l'herbe de croître près les mottes, que l'on forme à la fin comme une groffe tanvinière ; cette demière façon eft fouvent inutile quand il n'y a point d'herbe, \& gue la motte eft fuffíamment grolie. On peut meme les planter \& rehauffer à la charrue, ce qui eft bien moins difpendieux.

Au mois d'Catobre, on fair la récolte pa un

$$
\mathrm{C}_{2}
$$




\section{6}

beau remps; un homme enlève la motte avec I bêche ou un trident, il rête ordinairement trèsper de ces pommes dans le fond: de petites filles $\&$ de petits garçons font aux aguets, fecouent toute la terre des tiges, \& les ramaffent; l'on met ces pommes dans une cave pour les conferver \& les garantir de la gelée; au mois de Février, on les met au grenier, où elles fe confervent jufqu'aux nouvelles; il eft furtout effentiel d'en faire l'extraction plus tôt que plus tard, \& par un beau temps, de peur que la gelée ne l'atteigne \& l'empêche de fe garder; on doit préférer la groffe blanche tirant fur le jaune \& un peu applatie, ì toute autre efpèce, parce qu'elle réfifte mieux aux premières gelées, \& parce qu’elle ent un peu plus enfoncée en terre, quoiqu’en général toutes cherchent la terre douce, légère, ratiffée \& rapportée au haut de la groffe motre : cette récolte donne par le remuement un bon labour ì la terre qui eft déja bien netroyce : après cette opération, on bine \& on laboure le champ, on l'enfemence en bled dans la même année, comme toute autre terre en jachère, ou, pour mieux réufir, en bled de Mars, en orge, ou paumelle, dont tout Cultivateur prudent doit toujours avoir une portion en réferves pour fuppléer aux gtains d'hiver péris ou gelés; 


\section{7}

les Gouvernemens devroient mếme encourager la culture de ces grains printaniers, qui empêcheroient une difette défaftreufe, \& obvieroient à de grandes calamités. Ce fol bien ameubli par les façons données à la pomme de terre \& par fa récolte, qui équivalent aux labours des terres en repos, rapportera donc encore un bon bled \& d'autres bons grains de Mars.

\section{A R T. V I.}

\section{Carotte.}

On sème les Carottes depuis le is de Mars jufqu'au is d'Avril, felon le remps quil fdit; le plus tôt eft le mieux; deux livres \& demie à l'arpent fuffifent. Elles réuffiffent à merveille dans les terres douces \& limoneufes, dans des fonds ou vallées argilleufes, mais pas trop roides. On laboure ces terres avant l'hiver ì la charrue ou à la bêche, d'un bon pied de profondeur; il faur adoucir la terre, au printemps, avec la herfe, femer, puis herfer le femis.

Quand les Carottes font bien levées, on nettoie les mauvaifes herbesà la main ou avec la houre, on ratiffe bien la terre, \& on les réduit à un demi-pied l'une de l'autre; on redonne encore un fecond travail 
38

à la houe pour détruire les mauvaifes herbes, jufqu à ce yue le verd des Carottes couvre la fuperficie du terrein. Au commencement de Novembre, on arrache les Carottes; on coupe le verd, excellent pour le gros bétail, on met les racines à labri de la gelée, en tas ou dans de grands trous qu'on recouvre de terre comme une tombe; on conferve de même les pommes de terre \& autres racines. C'eft une excellente nourriture pour les vaches: elles donnent d'aufli bon lait l'hiver qu'on puiffe le defrer. Cette plante rafraîchit les chevaux \& les engraifre. Enfin, tant que la luzerne ne foit venue, elles font le plus grand profit dans une exploitation; plus on en a, mieux on s'en trouve. On sème également du bled après les Carottes, comme après les pommes de terre. Je ne parlerai point des panais, bettraves \& racines de difette, parce que c'eft la même culture, qu'on en retire le même profit que des Carottes. Il eft effeniel que tout Cultivateur ne néglige pas plus leut culture que celle des Carottes. 


\section{A R T. V I I.}

\section{Navet.}

On sème les Navets communs, ronds \& plats au mois de Juin, vers la Saint-Jean, dans une bonne terre douce, bien fumée ou bien graffe; on met à-peu-près une livre de graine à l'arpent. Quand les Navets font levés, \& qu'ils ont deux ou trois feuilles, on y jette l'urine des beftiaux; cetre opération doit être faite à la veille d'une pluie, rien n'accélère plus leur croiffance, ils deviendront très-gros. Le Navet \& fa verdure font excellens pour les bœufs \& les vaches, perfonne ne l'ignore; il faut en avoir en tont temps, autant que faire fe peut, mais particulièrement l'hiver, on en tire le plus grand profit. On engraifle des bœufs \& des vaches avec les carottes, panais, bettraves \& les feuilles de haut choux; celles-ci donnent alors autant de lait \& d'auffi bon beurre qu'en été.

On sème encore des Navets après la récolte du feigle, quand la terre n'eft pas maigre; mais il faut fur-tout femer au mois de Juin ou Juillet la rabba ou turnips: c'eft la rabbiola des. Provinces méridionales de France, elle fort de 


\section{0}

corre; n'y tient que par le bout de la racine. clle devient très-groffe; $c^{\prime} \in f$ une excellente nour. riture pour les bêtes à cornes \& les porcs, \& on doit toujours en femer beaucoup pour en avoir tont lhiver, \& les conferver comme les caruttes, panais \& bettraves dans des trous faits en terre: On sème également du bled de Mars ou d'hiver après les Navets comme après les autres efpèces précédentes.

\section{$A$ R T. $V I I I$}

\section{Choux.}

On sème la graine de haut choux dans une bonne terre bien gralle \& bien fumée, au mois de Mars ou Avril ; on les replante au mois de Juin dans wne terre voifne de la ferme \& des étables, ainfi que les carottes, panais, bettraves, navets \& pommes de terre; on les a plus tôt fous la main \& on ne perd pas tant de temps par les voitures; on les engraiffe avec l'urine des beftiaux: ils viennent alors de quatre pieds de hauteur; on ratiffe auff autour du pied, il doit être à trois pieds de diftance; la tige eft toute garnie de feuilles depuis le haut jufqu'en bas, on arrache celles d'en bas toujours les premières au mois de 


\section{$4 x$}

Novembre \& Décembre, on en fait de très-bon breuvage pour les vaches avec du fel, du fon ou de la mouture, \& fur-tout pour les élèves; rien ne les fortifie mieux \& rien ne les empêche tant de languir ; on doit toujours en avoir beaucoup, ils réfiftent le plus long-temps à la gelée. Cette graine eft très-commune en Flandre, une livre fuffit pour un arpent de terre, ainfi que les navets \& le colfat. Il faut que le fel foit commerçable \& point coûteux; il eft auffi effentiel à la fanté des animaux qu’à celle des hommes. D'ailleurs, le fumier acquiert une qualité exquife \& précieufe pour les terres, quand on donne du fel aux beftiaux.

\section{$A R$ T. I X.}

$$
\text { Ris - fec. }
$$

M. Poivre a rapporté de fes voyages une ef́pèce de Ris connu à préfent en France, \& qui y réuffit très-bien ; on le sème $\&$ on le récolte dans un terrein fec, fans quil ait befoin d'irrigation, d'où lui vient le nom de Ris-fec. C'eft la même culture que pour la paumelle, l'orge printanière \& les autres grains de Mars; il feroit d'une grande reffource devenant indigène. On fait combien ce. 
grain eft utile dans les temps de difette, \& combien l'urage cn eft agréable \& falubre, au milieu. même de l'abondance. C'eft pour tous les âges de la vie un mets délicat \& fain; fa culture oft facile comme celle des autres grains de Mars : il exige aufii peu de dépenfes que de foins. On peut le joindre à prefque tous les autres alimens; les Indiens qui font bien plus près que nous de l'hemreufe fimplicité de l'âge d'or, préfèrent le Ris à toute autre nourriture, \& cet excellent farineux contribue à leur rendre le fang pur \& calme, \& par conféquent le caractère doux.

Cependant, joint avec les viandes que notre agriculture produira plus abondamment, il fera. un aliment fort \& folide qui infiue néceffairement fur un tempérament robufte; il faut le propager dans nos campagnes où règne trop de misère.

La multiplication des beftiaux produira une abondance de fuif, de beurre, \&c., qui enrichit l'Trlande. Le commerce des groffes \& menues falaisons, de pelleteries nous fera fortir noins de numéraire pour les cuirs de Hongrie \& autres, que notre induftrie apprendra bientôt à façonner: nous pourrons même en fournir aux étrangers. Que de richeffes perdues pour nous, parce qur: 
nous laiffons notre fol dans l'inertie, que l'induftrie françoife fauxa bientôt vivifier au-delà de ce que je puis exprimer.

Or, je fuis perfuadé qu'on peut totalement fupprimer les jachères, d'abord dans les bons fonds, puis dans les médiocres, \& graduellemene dans les mauvais fols, par les fecours des prairies arrificielles, des beftiaux \& des fumiers \& autres engrais, \& du fel \& du tabac vendus librement; parl'abolition des fuppôts de la Gabelle, des Aides \& autres Vampires du Royaume; enfin par un impôt unique \& direct, mis fur les revenus des fonds ruraux \& autres. Toutes les impofitions indirectes font ruineufes, \& détruifent les richeffes des champs \& du labourage.

Le monopole n'affameroit jamais un pareil Royaume; ceux qui voudroient l'affamer, femblables à Tantale, mourroient plutó de foif \& de faim au milieu de leur or $\&$ de leur argent, $\&$ le Laboureur vivroit tranquillement avec fes denrées \& fes beftiaux, il repoufferoit de fes bras nerveux celui qui voudroit l'armer contre fes Concitoyens en lui promettant des richeffes qu'il méprife, parce qu'il n'en a aucunement befoin. 


\section{A R T. X.}

\section{Tabac.}

Les bas-fonds, gras, noyés ou expofés à l'être de quelque nature qu'ils foient, doivent avant tout être faignés par des foffés dont un bout au midi, \& l'autre au nord, \& , fi les premiers ne fuffifent point, par des foffés tranfverfaux. La terre tirée des folfés, fi elle fe trouve toujours d'une nature bien graffe, mêlée avec celle de la fuperficie, pourra être mife auffitôt en culture, à moins que ce ne foit des cailloux, rocailles, crayon ou tourbes, \&c. On y plante ou repique du tabac aul printemps, femé avant dans une couche ou dans un jardin ou terre fort graffe \& fumée; on ratiffe la terre autour, quand la plante sélève, comme aux pommes de terre; tous les rejets latéraux \& ceux du fommet quii veulent monter en graine doivent être coupés, à mefure quỉls fe montrent, avec l'ongle du pouce : il doit être planté en rangées égales; les rangées font à detux pieds l'une de l'autre, \& chaque plante à un pied de-diftance, on lailfe croître huit ou neuf feuilles avant de châtrer la fommité, ì demande beaucoup d'affiduité pour couper les rejets laté- 


\section{5}

Saux \& pour ratiffer \& remonter la terre autour de chaque plante; mais des femmes \& des petits enfans font cette befogne fans beancoup de peine ( $I$ ).

Les tabacs venus en maturité, même dans des fonds feptentrionaux \& très-froids, ne laiffent point que d'être recherchés par les Marchands qui les font paffer pour des tabacs de l'Amérique \& des Pays lointains, quoiqu'ils en faffent les dégoûtés pour les payer au plins bas prix pofible ; c'eft une branche d'induftrie quaucun Souverain ne doit négliger, puifque l'ufage en eft devenu auffi univerfel, \& qu'il pourroit ramener un numéraire immenfe payé par l'étranger ; on coupe la tige avec les feuilles, on les met en groffes bottes qu'on emporte pour faire fécher contre les parois \& les couvertures des maifons $\&$ des granges couvertes de chaume, puis on l'effeuille l'hiver quand il eft fec; pour le mettre

(I) Il eft sûr qu'on paie douze millions à l'Etranger pour les tabacs importés; fi la culture en étoit libre en France, on pourroit en vendre pour douze millions aux Peuples voifins, \& avoir fa confommation fans nuire aux autres cultures. On fe pafferoit de Commis, de régie, qui tue \& tuera toujours toute économie rusale. 
tous grains huileux \& effentiels pour les manufacures, la marine \& les arts ; \& même les oignons qui y viendroient aufh gros que ceux d'Egypte. Je n'expliquerai point la culture de toutes ces graines qui n'eft que trop connue, j'en ai domé plufieurs mémoires imprimés dans quelques journaux françois, il y a long-temps. Les fonds ici défignés doivent être mis en avoine ou en orge, pour pomper l'exubérancé des fucs \& des fels nourriciers; on la donne en verd, fi elle vient trop forte, finon on la lailfe mûrir, il faut y femer le printemps fuivant du chanvre, le printemps d'après du lin ramé par un beau temps, après avoir bien adouci la terre à la herfe, à la charrue, puis des cillettes, \& alternativement du lin, du chanvre, des oignons, de l'avoine, tant que la terre ne foit plus trop forte, \& qu'elle puiffe être femée en bled avant l'hiver, ou en bled de Mars, orge, paumelle, riz-fec.

Urit enim lini campum feges, urit ayena;

Urunt lathoeo perfufa papavera fomno;

Sed tamen alternis facilis labor. . . . . . .

Virg. Georg. Lib. I:

Toutes ces plantes defsèchent ces terres graffes $\&$ humides, \& les difpofent à porter du froment: 


\section{3}

le Colon y trouve un très-grand profit fans dépenfe d'engrais ; tous ces grains font femés aul printemps; ils ne courent pas les rifques des hivers trop rigoureux ou trop doux, qui font périr le plus fouvent ces grains d'hiver.

Il eft de ces fonds privilégiés par leur pofition \& leur qualité fupérieure, qui rapportent tous les ans des récoltes très-abondantes \& très-précieufes. Ces terres femées en lin portent encore immédiatement après qu'il eft enlevé, dans la même année, une feconde dépouille, foir en navets; foit en plançons de colfat : ces fruits, loin d'épuifer le terrein, ne font que le rendre plus propre à porter de bon froment \& de bon feigle, \&c., qui auparavant auroient fondu \& feroient pourris dans le champ. Quand donc cette exubérance des fúcs eft enlevée, on cultive cette terre comme tout autre champ mis de longue main en culture, en femant du colfat, du bled, vefce, hivernace, féve, lentille, avoine ; ce font autant de récoltes gagnées fans dépenfe d'engrais.

Sic quoque mutatis requiescunt fctibus arya. Virgil.

Rien n'eft plus vrai que la variété des fruits \& des productions répare les terres : $\mathrm{Si}$, nonobftant tous ces foins, on voit, dès les premières dépouilles; 
dépouilles, que les herbes étouffent les productions; quand le gazon eft pourri, on resème ces terres en avoine; auffitôt qu'elle eft levée, on $\mathrm{y}$ sème quinze ou vingt livres de trèfle à l'arpent, qu'on donne l'année fuivante en verd au bétail, tant qu'il dure; l'année fuivante on le Jaiffe engazonner \& enherber : il deviendra un excellent pré à faucher, ou à faire brouter par le gros bétail.

Dans toute la méthode ici expofée, je crois quil y a un profit réel, bien plus avantageux que de laiffer en friche de bons terreins; le Cultivateur y trouve toujours du bénéfice, plus d'engrais \& plus de moyens d'amélioration; on fauche plus fouvent les prairies artificielles que le pré naturel qui ne donne qu'une fois, puis un regain.

On objectera quil y a moins de frais, moins de dépenfes pour ce dernier : oui, fans doute; mais ne font-ils pas bien compeníés par le produit de toute efpèce? Par-tout où on travaillera la terre, comme je crois l'avoir fait fentir, on aura plus de beftiaux ; outre cela, on récoltera plus abondamment du froment, méteil, feigle, orge, mais ; en fus \& en pur gain, des lins, colfats, chanvre, camomille, lentilles, vefces, fèves qui fourniffent deš nourritures aux hommes, Reftaur. de l'agriculture, Ex. D 


\section{Si}

pre ordinaire ou natrit; fi ce n'eft quils fourniffent des foin fi abondans \& d'une qualité fi exquife, quil y auroit de la folie à les défricher.

Pour peu gu'on life l'hiftoire des anciens Peuples, on voit quils ont toujjours eu des bois immenifes à abattre, à deffécher des bas - fonds qui rendoient le pays mal-fain \& inepte à la culture; les bêtes féroces dominoient impérieufement cette nature agrefte : le travail \& l'induftrie de l'homme actif ont tout furmonté. Dans le NouveauMonde, ce font les mêmes opérarions: ceux qui cultivent d'abord les terreins élevés \& arides, fe rebutent bientôt ; redevenus plus fages par leur expérience propre, ou celle des voifins, ils abandonnent les hanteurs pour deffécher \& cultiver les plaines \& les fonds bas quils avoient négiligés. Ce changement ne doit furprendre perfonne, puifque dans l'Europe, depuis fr long-temps policée, \&r aujourd'hui fi éclairée, il faut que des Sociétés patriotiques propofent par-tout des prix, pour convaincre les Gouvernemens de l'utilité des defféchemens \& des profits qu'on peut retirer des marais qui, pour la plupart, font des bas - fonds.

Auffi la première dépenfe pour les marais doir être faire par le Gouvernementr; cette opération 


\section{2}

mérite l'attention des propriétaires patriotes les plus puiffans \& les plus éclairés : s'il faut descanaux pour faciliter l'écoulement des eaux, sil faut les faire paffer par les poffeflions des petits \& des grands propriétaires, sil faut fupprimer des moulins à eau nuifibles, \& inondant tout un pays, les particuliers feront-ils en état de fe faire entendre, feront-ils écoutés ? d'ailleurs iront-ils expofer à l'aventure leur petit pécule, pour un bien futur dont ils n'auront peut-être aucun profit? C'eft donc au Souverain à mettre la première main à ces travaux, \& à encourager les cultivateurs patriotes qui s'expofent à des tentatives fí périlleufes : c'eft une avance foncière dont plus tard il eft amplement dédommagé ; à la place de ces eaux incommodes dont il n'a aucun tribit, autcun denier, vont naître des grains, des beftiaux de teute efpèce, des abeilles, de la cire, du miel, \& des hommes effentiels à la culture, \& d'autres pour le commerce, les manufactures, les atts, la marine \& la guerre : fi elles reftent croupiffantes, leurs exhalaifons empoifonnées porrent dans tout le pays le germe des maladies les plus rebelles \& la mort.

Il me femble que cet expofé fair affez fentir l'utilité de cette méthode, la préférence qu’elle 
53

mérite, \& fa fupérionité fur tant d'altres qu'or. vante beauconp; tout ce que j'avance eft fimple, \& appuyé fur l'expérience la moins fufpecte : toutefois pour ne point courir le hafard de fe tromper fur un ouvrage de pure théorie, on pourroit faire l'épreuve \& les effais en petit de tous ces travaux -gui n'appauvriroient perfonne.

On objecera peut-etre que dans la manière que l'on propole ici de défricher \& de cultiver, on ne voir point d'année de repos, point de jachère : non vraiment; c'eft là le principal but : fi les hommes ne fe rebutent point de manneuvrer ha terre à la charrue \& fur-tout à la bêche, de l'aider d'engrais par le moyen des prairies artificielles \& des racines, telles que pommes de -terre, carottes, panais, betteraves, navets, \&rc., ils ne manqueront jamais de fubfiftance pour eux \& pour leurs beftiaux, \& par conféquent de fulinier: la terre n'eft jamais laffe de produire des fruits profitables. A bandonnée à elle-même, elle en produit de mauvais \& infalubres, il faut la remuer avec une bêche d'or: cette culture n'exclint done point celle du bled, du feigle, de l'avoine, des fèves, des fcourgeons, du lin, du colfat, des willettes, \&rc.; au contraire elle la facilite \& la córrobore : les fords qu'on deftine an fain-foin

$D_{3}$ 


\section{4}

\& à la luferne ne font furement pas les meilleurs; ils font en repos pendant $S$, IO, Is ou 20 ans, plus ou moins, felon la qualité du fol; ils donnent le temps de rejetter rous les autres fumiers fur les meilleures terres qu'on cultive pendant ce temps, felon l'ancienne routine, avec profir, en froment, lin, colfat, \&c., parce que les fumiers provenans des pailles font préférables pour les grains, parce que les cendres de tourbe, de bois, fuie de cheminée, cendres d'houille, chaux, urine des beftiaux, latrines, \&c. ; conviennent mieux aux prairies artificielles.

Si l'on met des pommes de terre, carottes; panais, betteraves, navets, choux, ce n'eft jamais dans une grande quantité de terres; ce n'eft qu'à proportion de fes beftiaux \& de fon exploitation : on a toujours, malgré la récolte de ces fruits effentiels \& précieux, le même nombre de terres, ou peu s'en faut, en bled, enfeigle, en avoine, en fcourgeon, \&xc., comme dans les foles réglés \& de repos; le colfat, lin, cuillettes, fèves, carottes \&c: tiennent lieu de jachère; on sème du bled immédiatement après leur dépouille, fans laiffer la terre en repos. Voilà la vraie richeffe d'un Colon intelligent, qui jetre de lor à propos fur fes terres par des avances 
55

foutenues \& réitérées qui le dédommagent roujours amplement de fes mifes, de fes foins \& de fes travaux par la fuppreftion des jachères.

Un royaume qui a quatre cents millions de revenu, en aura fix cent millions; \& bien plus, lorfque tout fera dans un état de floriffante culture, je trouve cette augmentation dans les grains huileux, tels què colfat, lin, chanvre, asillettes, \&c., qui donnent l'aliment au commerce, \&. qui occupent utilement l'année de jachères; dans l'augmentation des beftiaux, des fuifs, des falaifons, des pelleteries, des laines perfectiónnées, des nourritures, des fumiers, \&x. La terre ne fe laffe jamais quand on l'engraiffe \& quand on la cultive bien; ce font les hommes inexpérimentés \& pauvres qui fe laffent \& fe rebutent; rien donc n'eft plus vrai qu'elle rend en proportion de ce qu'on lui donne; mais comme je l'ai dit, l'alternative \& la variété des productions réparent \& renouvellent les terres; les engrais nouveaux la rendent plus productive \& plus profpère.

Dans la culture des jachères, la terre produit toujours les mêmes fruits depuis le commencement d'un fiècle : dans la première année, du bled, méteil, feigle ou orge; dans la feconde

D. 4 
année, de l'avoine, vefce, ou lentille; enfin l'année du repos ou de jachères pour la troifième année, \& c'eft tonjours le même cercle \& la mème ritournelle jufqu’à la fin des fiécles. Par Il méthode propofée, il nait un nouvel ordre de chofes, il fe fait une autre révolution dans les efprits \& dans la culture ordinaire.

Je dèmande à tout homme de bon féns, files fucs \& les fels propres \& convenables à la croiffance du bled, feigle, avoine, \&c., ne doivent point s'épuifer par une longue fuite d'années, danș des fonds qui ne font pas riches \& privilégiés par leur nature, qui ne font jamais profondés à lá bêche ni à la charrue, ou par de nouveaux engrais, d'autant plus que les principales racines de ces efpèces font en griffe \& n'atteignent que la fuperficie du fol, qui fouvent n’elt remuée que par de chetives charrues \& des labours légers; au lieu que dans la façon que j"indique, on mancuvie bien autrement la terre : on la profonde, on la renouvelle, on la rajeunit, on l'engraiffe beaucoup plus, \& on le peut, parce que l'on a plus de beftiaux, plus de cendres, plus de chaux $\&$ all tres engrais nouveaux, \& en fus plus de fumier: Le plus grand nombre des efpèces que je propofe s) cultiver, tels quie fain-fom, lifferne, trefte, 
chanvre, colfat, lin, oillettes, fèves, carottes; $\& c$. , ont des racines longues \& pivotantes quí vont puifer au plus profond du fol, des fucs vivifians \& nouveaux, \& cependant morts dans l'autre culture. Les cendres de tourbe, la chaux mêlée enfemble, les fumiers \& les engrais tournent donc encore au profit des fromens, méteil, avoine, \&c. que ces racines n'ont point fucés. On peut donc par ces moyens, \& pecit à petit, fupprimer les jachères.

Ceci me parốt fi clair, fi fimple \& fr facile à pratiquer, qu'il feroit fuperfu de s'étendre davantage là-deffus; mais les gens de la campagne ne s'en rapportent point, pour l'ordinaire, aux follicitations ni aux mémoires écrits : il leur faut des démonftrations palpables, parlantes aux yeux \& fortifiées par les épreuves, l'exemple \& les fuccès d'un étranger ou d'un voín : ils s'en mocquent malgré cela dans le commencement, parce quil cultive autrement qu'eux. C'eft bien parmi certe claffe d'hommes que les préjugés font plus difficiles à vaincre \& à furmonter : les femonces \& les injonctions n'y font rien; il faut donc prendre des voies plus douces, \& cependant qui atteignent plus surement le but qu'on fe propore: c'ent le bon exemple d'un propriétaire \& d'un agriculteur riche 
59

édit mal combiné, fait autant de tort à vos états. que le vent fec \& brûlant du midi, ou la gelée hots de faifon en fait aux fruits, aux campagnes verdoyantes \& fleuries qu'ils defsèchent entì̀rement.

La guerre peut faire périr des millions d'hommes; vous pouvez, ô potentats, ô peuples libres! fans beaucoup de peines, faire fortir du néant des milliards de générations nouvelles : protégez le cultivateur contre la finance, la chicane, \& toute oppreffion maltotière; encouragez-le, rendez-lui la liberté \& la nobleffe de fon premiet état; il fera riche, \& vous très-puiffans. 
MET WODE-pratique de semer et planter. le colsat à la manière flamande.

Imprimée à Paris, au Bureau royal de correfpondance générale, rue des Deux-Portes Saint-Sauveur, Février I 773 .

Ninil agricultulâ melius, nihill ubierius, nihil homine libero dignius.

Cic. de Offic.

K y a trois fortes de terres; la glaife, le fable, la marne. La glaífe, mêlée avec une portion de fable, eft ce qu'on appelle argille. Les différéntes combinaifons, les différens mélanges de ces terres compofent la variété infinie de tous les fols, \& c'êt ce qui leur fait donner ces dénominations particulières: marneux, où la marne domine; glaifeux, oì la glaife eft en plus grande quanzité; fableux, où le fable prévautr. A proprement parler, il n'y a que deux fortes de terres: l'une forte, \& ${ }^{2}$ l'autre légère; leur mélange leur fait donner différens noms. Leurs couleurs font aufi variées que leur nature \& leurs propriétés; la glaife eft Ia plus compacte \& la plus tenace, celle que l'agriculture doit le plus divifer, remuer \& rendre 
Gr

légère par le móyen du labourage, ou le mêt lange d'une autre terre, ou engrais plus léger. Le fable eft ordinairement léger, vole au vent Le labourage ne doit pas être î fréquent fur ce fol; mais il faut y multiplier les engrais les plus gras, les plus compacts pour lier fes parties incohérentes \& divifées. La marne pure \& propre a. faire de la chaux, eft excellente pour échauffer les terreins froids \& humides; la marne sèche, craye ou crayon y eft propre auffi, mais principalement pour divifer les fonds glaifeux, trop argilleux , \& dont les pores font trop ferrés. La marne graffe \& glaifcufe eft merveilleufe dans les fonds de nature légère; elle relie les parties féparées, \&r leur donne la confiltance néceffaire dont elles étoient dépourvues.

Je crois que la fcience du Labaureur fe réduit à rendre les terteins compacts affez divifibles \& fpongieux, pour que la ftagnation des eaux pluviales \& d'hiver ne pourriffe point la racine des plant is \& des grains, $l$ is abreuvant des fels inhérens au fol, de ceux dont l'atmofphère l'imbibe, \& de ceux dont l'induftrie du Cultivateur l'enrichit. Dans in fens contraire, les terreins trop légers qui volent au vent ou s'affaifent trop (ce quit met à découvert toutes les racines, les fait geler ou langair, périr enfin), doivent fubir une opé- 
ration touke différente, \& qui donne du corps \& de la confiftance à leur légèreté. La plupart des fonds fur lefquels l'agriculture n'exerce pas toute fa vigueur, ne font jamais remués bien profondément. Quand, en fillonnant la terre, le Laboureur ramène à la fuperficie une terre plus dure; plus compacte, ou d'une couleut différente de la couleur ordinaire, il dit: cette terre ne vaut rien; il n'ofe la percer plus avant; de forte que l'eau féjournant toujours fur cette croûte, réfroidit le fol, empêche la végétation, le pivotement dés racines, \& nuit on ne peut pas davantage à l'accroiffement des plantes. En ruifclant la terre de huit pieds en huit pieds par planches égales, on commence à donner un écoulement aux eaux; le mélange de la terre, tirée du fonds des rigoles ou ruiffeaux dont nous parlons, avec celle de la fuperficie, va rajeunir tout le fol: deux ou trois ans après on renouvelle la même befogne, c'eft-à-dire qu'on ruiffelle encore la terre dans l'endroir le plus bombé, ou le milieu des anciennes planches. Le fein de la terre, ainfi déchiré à fonds par plufieurs reprifes \& en tout fens, ne fera plus noyé; les racines trouvant une terre meuble, s'étendront en liberté, \& pomperont les fucs propres à leur efpèce; les fonds de la Flandre, bons ou médiocres, ont été fi fouvent ruiffelés \& déchirés die 


\section{3}

long $\&$ de large, en croifant, \& de tant de mâz nières avec la charrue ou la bêche, que dans certains cantons, les pluis fubftanciels y font fort légers à une très-grande profondeur: ainfi, quelle variétét dans les productions du pays, quielle fécondiré! on la dit inépuifable. On l'attribue, mal-à-propos, à l'excellence du fol; elle n'eft due qu'au travail, à la dépenfe continuelle \& à l'induftrie infatiguable de fes laborieux habitans. Les engrais y font: fort chers: peui importe, il faut en avoir; on en fait, on en achète à quelque prix que ce foit. Ouio Mais, dira-t-on, il faut bièn de l'argent \& des richeffes pour fournir à toutes ces dépenfes: j'en conviens, aufí dit-on quil faut remuer la terre avec une bêche d'or, que l'agriculture hait patvreté; que fans avances on ne peut faire aucune dépenfe, \& fans dépenfe, point de récolte; enfin, pauvres Laboureurs, pauvres moifons; pauvres moiffons, pautvres villages; pauvres villages, pauvres Provinces; pauvres Provinces, pauvres Royaumes. Ce préambule un peu aride eft cependant nécelfaire pour faire entendre la culture flamande du colfat \& des autres grains.

Autant qu'il eft poffible, il faut déchirer la terre avant l'hiver, ce que l'on appelle donner une 
64

taye avec la charrue qu'on nomme binè (I), Bincit ou binot. Enfuite il faut la herfer, puis y voiturer du fumier bien pourri. Cependant fi les terres font en bon étar \& affez graffes, il n'en faut pas, parce que trop de fumier fait venir la tige trop haute, moins bonne a planter, \& plus foible pour réfifter aux gelées; fi l'on n'a pas pu y. porter du fumier avant l'hiver, il faut néceffairement en mettre au mois de Mar's, lenfouir au binoit, puis herfer, enfin donner un fecond labour. avec la charrue tourne-oreille ou le brabant. Peu de temps après bien herfer, enfuite retoutner la herfe fur le dos avec lequel on applatit le terrein; ce qui empêche la séchereffe d'y pénétrer: en langage du Pays on appelle cela ploutrer. Vers le

(1) Bine, bino aures, fignifie charrue à deux oreilles immobiles.

L'autre charrue a une oreille de fer ou de bois, mobile, \& le brabant ou le loup qui a auff une oreille immobile, \& qui n'a point de roues; fon axe porte fur: un petit patin qu'on remonte ou hauffe à volonté, ce qui enterre ou déterre la charrue plus ou moins. Elle eit excellente pour les défrichemens \& les terres fortes; çeft la plus expéatitive \& la meilleure de toutes celles que je connois; on n'arrête jamais : on va toujours en avant, \& en tournant au bout de chaque champ.

premier 
premier de Juillet ou environ, il faut un troifitme labour avec l'une ou l'autre charrue; herfer \& ploutrer comme ci-deffus. Vers le. 20 du même mois on sème le colfat, on pince la graine avec le pouce \& les deux premiers doigts fuivans; pouil la femer, le femeur doit embraffer deux bons pas, fur-tout il doit fe garder de femer dru; un tour de herfe fuffit pour la couvrir; deux livres ou deux livres \& demie de graine fuffifent pour un arpent de terre.

A la fin de Seprembre, cette plante doit être arrachée avec la racine, mife en bottes pour être trainfplantée à la main, jufqu'à l'œillet, dans une autre terre qu'on prépare de la manière fuivante. Les feuilles les plus près de la racine font trèsbonnes pour les vaches.

On peut planter le colfat après toutes fortes de récoltes. La dépouille du champ étant enlevée, il faut biner ou binoter, c'eft-à-dire, labourer avec la bine \& la herfe, pour détruire l'herbe de la fuperficie, voiturer de bon fumier, (tous engrais font bons) enfuite l'enfouir avec la charrué toume-oreille ou le brabant, par planches; c'eft-à-dire qu'on trace huit raies, \& que la huirième refte ouverte; c'eft de ce fillon ouvert qu'on tire avec la bêche la terre qui, plus tard, Reftaur. de l'agriculture, Ec。 
- Techaufe, regarnit la plante du colfat, \& rajeinir le terrein. Ce font des femmes, des petits garçons, des jeunes filles qui plantent le colfat: ils en prennent un faifceau fur le bras gauche, de la main droite ils empoignent quatre ou cinq plantes plus ou moins, felon leur groffeur, les enfoncent: une à une, à-peu-près jufqu'à l'cillet, dans des trous qu'un homme vigourenx fait avec uin inftrument garni de deux groffes dents de fer. Cet homme va toujouts en reculant, brife les mottes, \& applanit le terrein avec les pieds. Sil y a trop de mottes, on paffe la herfe fur la planche pour adoncir la terre. Cet homme fait les trous par rangées \& routes. Chaque rangée a un pied; chaque plante eft à quatre pouces de diftance; chaque trou doit étre rebouché par le planteur, en appuyant le pied fur la terre près de la racine, comme on plante les choux ou les porreaux.

Vers le mois de Novembre, on envoie des ouvriers fur le champ de colfat: ils prennent avec une beche un bon pied de terre de profondeur \& un pied de largeur, dans le fillon refté ouvert de chague planche; ils jettent cette terre à droite \& à ganche entre chaque rangée, le plus près pofnble des racines, fans néanmoins couvrir les. ferilles \& la tige. Cette opération garantit la 


\section{7}

plante de la gelée, \& lui donne une nouvelle terre. Au prititemps, on prend encore ordinairement un demi-pied de terre, plus ou moins de profondenr, dans les ruiffeaux ouverts; ; on jette auffi cette terre entre chaque rangée de colfat, pour regarnir \& rechauffer les tacines, \& lui fournir une terre nouvelle qu'on tire également du fonds des milfeaux de chaque planche.

A la Saint-Jean on récolte ordinairement; Io grain commençant à noircir, on le fcie, on l'étend par javelles en atteridant qu'il foir affez mûr pour le battre fur le champ même, où on le met en meule pour attendre à le battre au mois de Septembre ou d'Octobre, fur une grande toile piès. de la menle : on le crible, on le vend pour faire de l'huile bonne à brûler, ainfr que pour les diaps, favonneries \& autres manufacuures. Le marc eft un très-bon engrais pour. les terres, \& fert auffi très-bien à engraiffer les bêtes à comes $8 c$. les montons. La gouffe qui l'enveloppe fers aufl de notirriture lhiver à ces deriners. Sa tigge ranoufe fert très-bien à chauffer le four, à couvrir les toîts: des maifons ruftiques, à la litière des beftiaux, quand on manque de paille. La cendre en eft merveilleufe pour la leffive; quand on en met Erop, fa force écorche les mains des Lavandieres 
La racine fert à chauffer les pauvres, tout eft bon dans cette précieufe production; mais le plus grand avantage qu'elle donne à l'agriculteur, c'eft de lui fervir de jachère ou d'année de repos, de rajeunir fon terrein, de rendre les terres qui font trop dures \& trop húmides, plus fpongieufes, plus légères, \&z plus propres à porter dans la fuite toutes fortes de grains, fur-tout du froment.

Cette plante donne du travail à quantité de manouvriers qui menrent de faim dans les Provinces cù elle n'êt point cultivée ; elle fournit beaucoup an commerce par fes huiles, commé à l'engrais dés beftiaux \& à l'amélioration des terres par fon marc.

En tenant lieu de jachères, elle donne à la fín les moyens de les fupprimer toutes. Si les Provinces qui ignorent fon ufage la cultivoient, il y auroit un ticrs des terres condamnées à repofer, qui: produiroient une excellente récolte (I), qui éclaire \& chauffe le pauvre à bon marché, couvre fa cabane plus folidement que le chaume ordinaire; lui fait tirer meilleur parti de fon petit champ $\&$. de fon bétail, lui donne les moyens \& l'envie de

(I) De manière qu'un Royaume qui produit, année commune, 800 millions, en produiruit au moins I 200 


\section{9}

eultiver le lin, les cillettes, camomilles, chanvre, garance \& autres productions précieufes qui l'enrichiffent, lui donnent la facilité de mieux payer les charges, de faire des defféchemens \& défrichemens, \& bannit enfin la misère qui tient depuis fi long-tems les habitans des campagnes dans un abrutiffement lérhargique \& déplorable.

Cette plante a un défagrément; c’eft que le lièvre, le lapin, le faifan, la perdrix en fŏnt fort friands, \& que leur chair, quand ils s'en nourriffent, contracte un goût huileux \& de choux; elle eft beatcoup moins fine que celle du gibier des landes, des bruyères, des terres arides \& incultes.

Un domaine bien cultivé qui procure un bon revenu affuré, qui tire les hommes de la pareffes de la mifère, du néant, ne nous dédommage-t-il point de ce léger inconvénient? lequel vaut mienx d'avoir une valte folitude, repaire de bêtes nuifibles, ou de beaux villages floriffans \& couverts d'une vigoureufe population, bien nourrie, qui paye gaiement l'impôt \& de bons fermages? Ces perites inftructions peuvent fuffire à de bons $\mathrm{Cul}$ tivateurs qui donneront l'exemple. Les haricotiers feront les derniers à le fuivre, parce qu'il en 


\section{0}

coûte beancoup de frais; des Laboureurs dans l'aifance \& peu clairvoyans mépriferont cette méthode ; mais l'exemple de la Flandre, qui s'êt toujours trouvée dans l'abondance, même au milieu des plus fortes crifes, doit faire ouvrit les yeux aux plus opiniâtres. C'eft dans certe Pro. vince qu'on ne voit plus un pouce de jacheres, $\&$ la terre rapporte deux récoltes dans la inême année. Il eft vrai que quand le commerce des grains farineux de province à province n'étoit pas libre, celui des huliles n'étoit point gêné; c’eft pourquoi les Laboureurs cultivoient davantage ce quils pouvorent vendre à profit, le colfat; le lin, chanvre, collettes, camomille, \&c.

\section{Conclujions.}

On voit que par la culture du colfar on peut récolter deux fromens en trois années : lapremière en froment, puis l'année du coliat qui tient lieu de jachère \& d'une très-bonne jachère, \& enfin la troifieme encore en fioment par de nouveanx fumiers par le remuement \& le renouvellement des terres; on peut de même, après le lin, les cillettes, les fèves, yefces, févelottes, \&rc., récolter immédia. 


\section{$7 \mathrm{I}$}

tement du fioment, du feigle, parce que, quand la terre eft bien graffe \& bien culivée, on a encore de bon froment après chacune de ces productions, \& par conféquent point de jachères.

\section{F I N.}






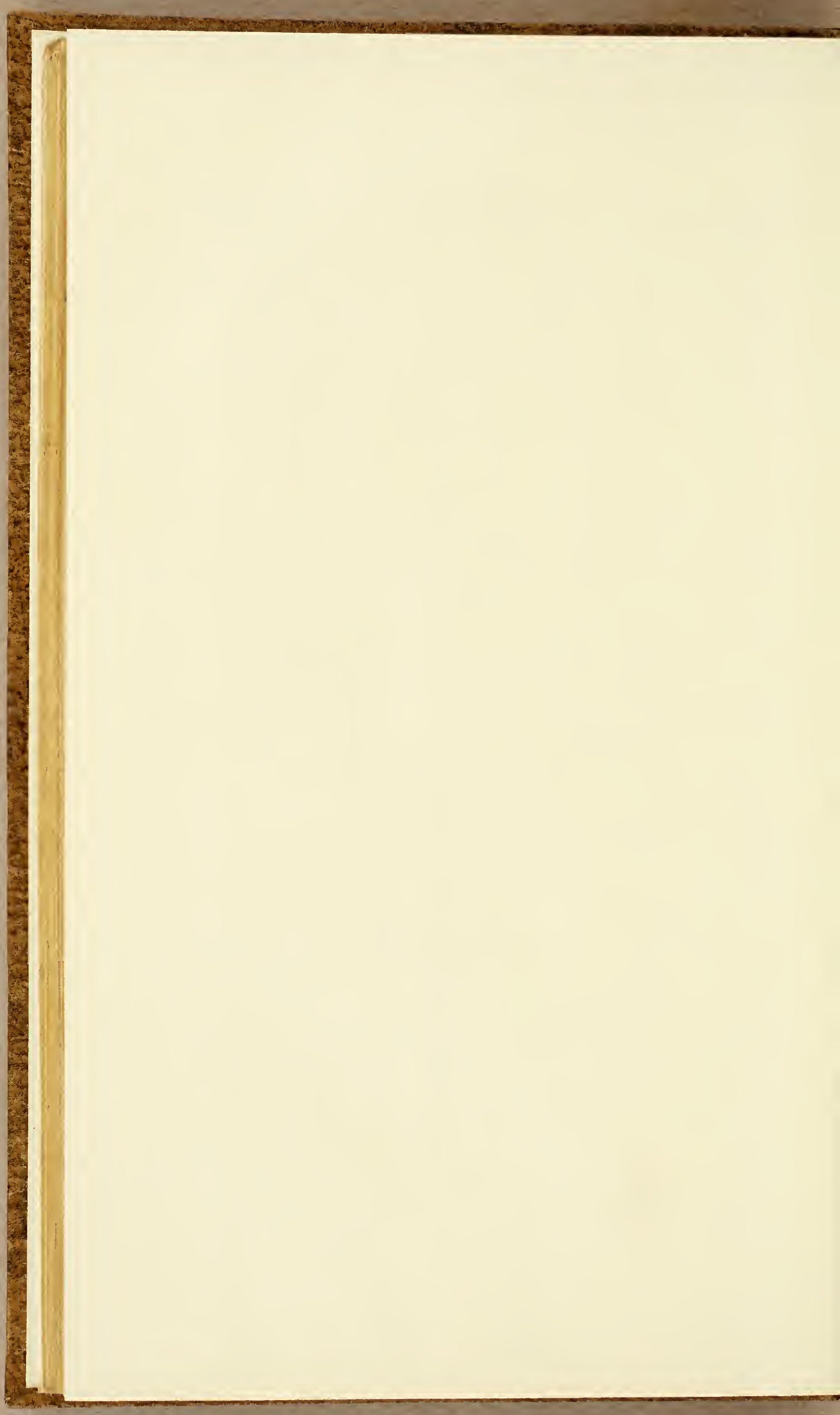





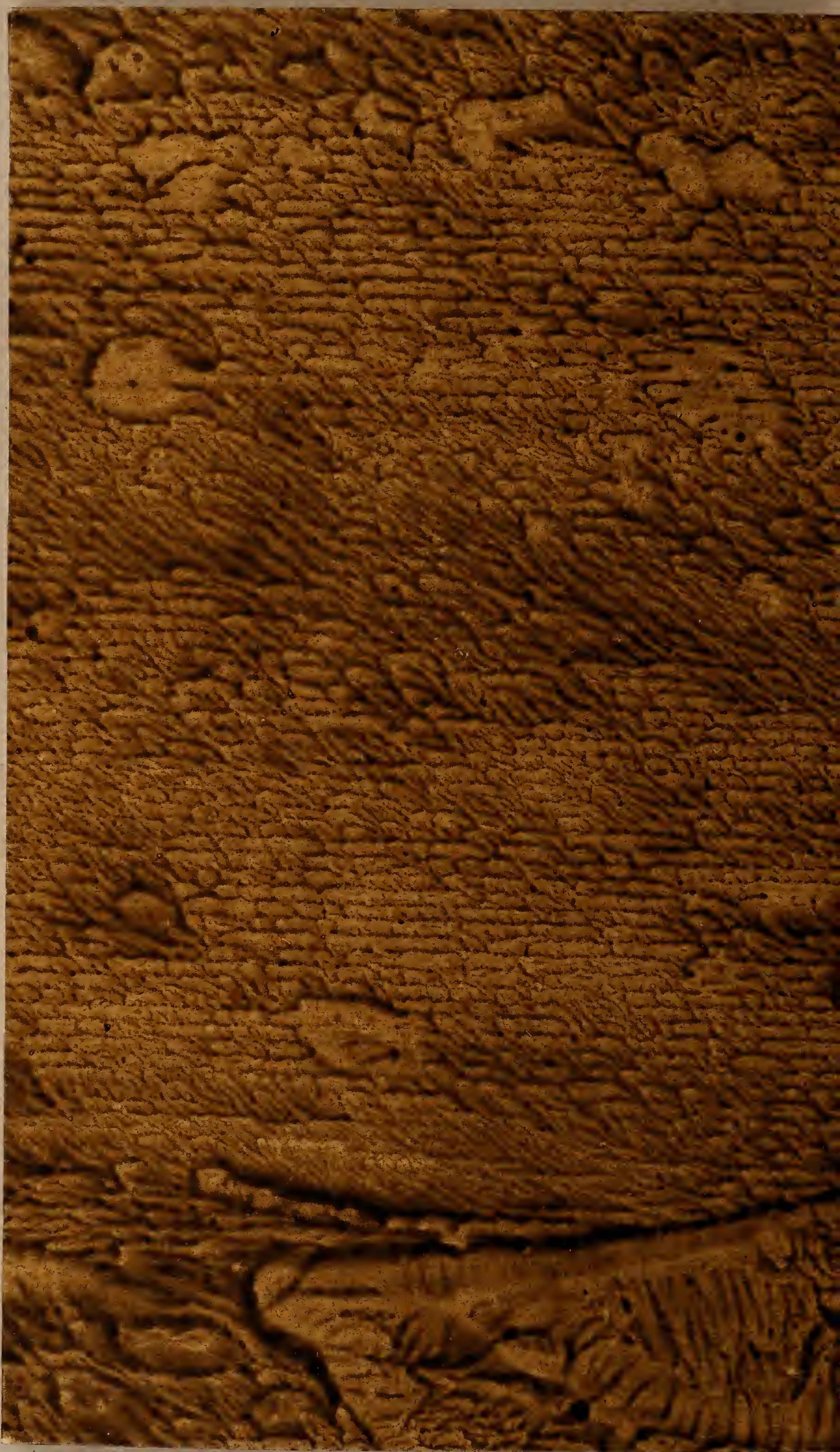

